\title{
'Technology is Everywhere, we have the Opportunity to Learn it in the Valley': The Appropriation of a Socio-Technical Enabling Infrastructure in the Moroccan High Atlas
}

\author{
Sarah Rüller ${ }^{1,3 *}$, Konstantin Aal $^{1,3}$, Simon Holdermann ${ }^{2,3}$, Peter Tolmie $^{1}$, \\ Andrea Hartmann ${ }^{1,3}$, Markus Rohde ${ }^{1,3}$, Martin Zillinger ${ }^{2,3}$ \& Volker Wulf ${ }^{1,3}$ \\ *11 Information Systems and New Media, University of Siegen, Kohlbettstr. 15, 57072 Siegen, Germany \\ (E-mail: firstname.lastname@uni-siegen.de); ${ }^{2}$ Cultural and Social Anthropology,University of \\ Cologne, Cologne, Germany (E-mail: s.holdermann@uni-koeln.de; E-mail: martin.zillinger@uni- \\ koeln.de); ${ }^{3}$ CRC 1187- Media of Cooperation (funded by the DFG), Siegen, Germany
}

Accepted: 23 April 2021

\begin{abstract}
This paper describes the appropriation processes involved in establishing a socio-technical enabling infrastructure in a valley in the High Atlas of Morocco. We focus on the challenges of coestablishing such an intervention in a rural/mountainous region that is already undergoing a process of continuous development and profound transformation. We reflect upon the changes and unforeseen appropriation by our local partners and inhabitants in the valley of a computer club primarily used as an informal learning centre for school children. We followed an ethnographic approach and combined research perspectives from both socio-informatics and anthropology. This paper sheds light on what a successful cooperation and intervention in this kind of challenging environment can look like. It does this by taking seriously competing expectations, fragile infrastructural foundations and the sociocultural context. Despite the challenges, the intervention managed to lead to the establishment of a socio-technical enabling infrastructure that plays a particularly valuable role in local educational endeavours and that is now moving towards supporting other members of the community. The paper thus provides insights regarding what has to be considered to create a mutually beneficial cooperation with all relevant stakeholders as well as a sustainable intervention.
\end{abstract}

Key Words: Appropriation, CSCW, Socio-technical enabling infrastructure, Imazighen, HCI, HCI4D, ICT4D, Computer Club, Morocco

\section{Introduction}

Information and Communication Technology (ICT) is becoming ubiquitous and, amongst people confronted with poverty, conflict and massive processes of change, it is beginning to have a significant impact. New technological developments have made it 
possible for groups that previously had rather limited access to ICT to become more visible. Political activists can more easily report their own experiences (e.g. Aal, Schorch, et al. 2018; Aal et al. 2019; Rohde, Aal, et al. 2016; Wulf, Aal, et al. 2013; Wulf, Misaki, et al. 2013), refugees can better organize the resettlement process in their host countries (Baranoff et al. 2015; Xu et al. 2015) and young and adult women can find new opportunities for empowerment in rural areas (e.g. Hoan et al. 2016).

The integration of socio-technological innovation in the area of education has produced particularly notable benefits (e.g. Aal et al. 2015; Ahmed et al. 2015; Ndaiga and Salim 2015; Stickel et al. 2015; Rüller and Aal 2020). This applies more broadly to the development of cooperation, with ICT providing access to educational material and online courses (Ahmed et al. 2015; Dias et al. 2005). ICT has been globally accepted and recognised as an educational resource (for both reform and facilitation) that can enhance and develop the skills that young people need to participate in and successfully meet the demands of the contemporary economy.

According to the World Bank's 'Morocco Education Support Program' proposal, between 2001 and 2015 the Moroccan government spent 30.4\% of its entire budget on the education sector. This had decreased to a still significant 25\% in 2019 (The World Bank 2021a, 4). However, there is a big gap in the relative proportion of children receiving pre-primary education between urban and rural areas, $60 \%$ vs. $36 \%$, respectively (The World Bank 2021a, 4). Due to enormous investments, primary school education inequality has decreased, but lower secondary school education still showed an urban-rural imbalance of 75 vs. $37 \%$, respectively, in 2017 (The World Bank 2021a, 4).

With regard to improvements in infrastructure, the World Bank Group has provided significant support in helping to improve living conditions in Morocco (The World Bank 2021b). One program includes rural investment (funding for roads infrastructure, electricity, water access, schools, health, etc.) and urban investment (illiteracy, housing conditions, unemployment rates, etc.) (The World Bank 2021b, 2). A key overall goal is giving vulnerable groups, such as poor, female and young members of the population, greater access to basic infrastructure.

The number of internet users in Morocco has risen dramatically from less than 14\% in 2008 to almost 60\% in 2017 (OECD 2018, 36; The World Bank 2019). Despite this increase, however, the Kingdom is still struggling to provide adequate access in rural regions. Thus, there is still a digital divide inside the country (World Bank Group 2018). In the Digital Morocco 2013 plan, the Kingdom stated that it was aiming to equip $100 \%$ percent of public schools with IT, with household subscriptions already having risen from 10\% in 2008 to around 33\% in 2013 (Kingdom of Morocco 2008, 19). 33

Appropriation has been a topic of interest in $\mathrm{HCI}$ and $\mathrm{CSCW}$ research for years (Orlikowski 1992; Dourish 2003; Draxler et al. 2012; Tchounikine 2017; Unbehaun et al. 2018). It refers to the process of incorporating objects into one's life and the emerging mechanisms and changes in practice through implementation into one's life (Draxler et al. 2012). Closely related to appropriation is the notion of an 'enabling 


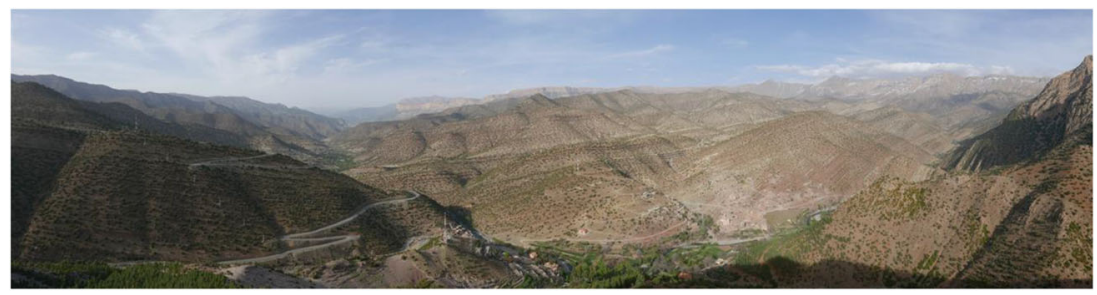

Fig. 1. The valley in the High Atlas where the research took place

infrastructure', i.e., an infrastructure that enables users to work or create something in an independent or collaborative manner. This term is primarily used in the field of information systems and development. It builds upon pre-set conditions of self-organization and the exploration of possibilities (Mitleton-Kelly and Papaefthimiou 2000), as well as on simultaneous interaction, flexibility and failure tolerance (Blecker and Graf 2003).

This paper describes the establishment and appropriation processes of a sociotechnical enabling infrastructure in a setting that was, and still is, replete with contradictions. By a socio-technical enabling infrastructure, we mean a space equipped with a variety of ICT devices and tools that can enable and encourage exploration. The mountainous region of the High Atlas we are working in is still, in some ways, a rural backwater (see Fig. 1 and 2). Yet, at the same time, it is undergoing a steady and profound transformation, and is the subject of (trans)national reform and development efforts. In the mountains and deserts of Morocco there is virtually no industry, no economic prospects and massively pent-up demand in the education sector (e.g., schools are currently still being built.)

This paper is addressed to the following research questions: a) What are the challenges and opportunities encountered by a socio-technical intervention in this

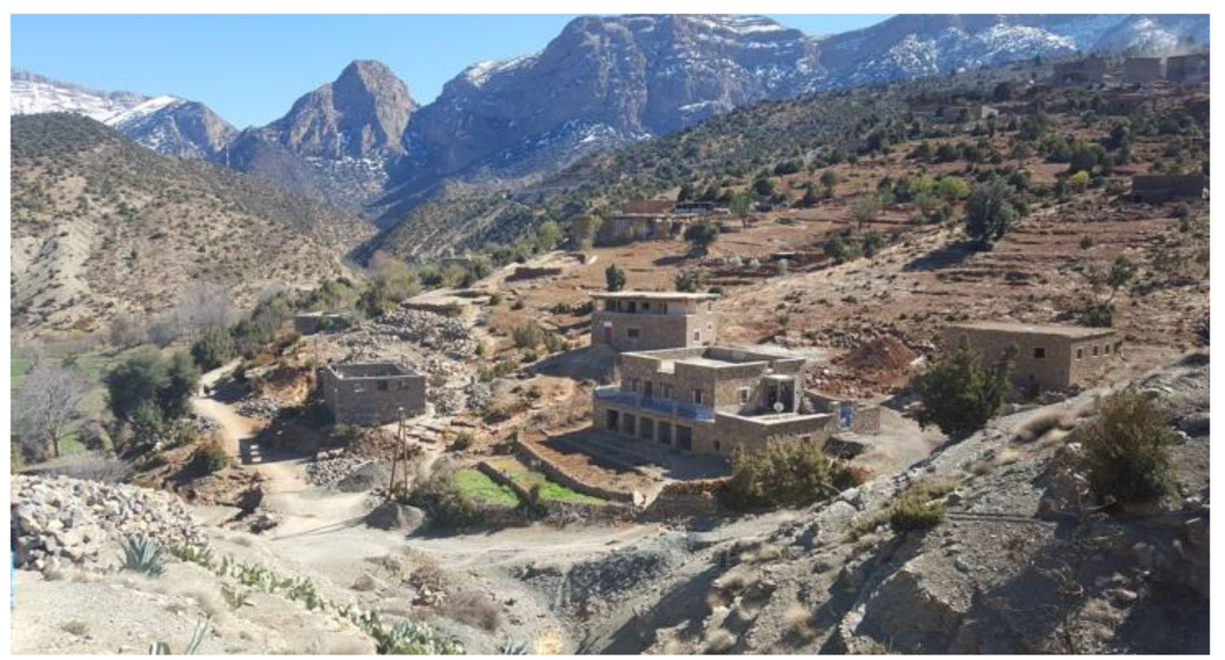

Fig. 2. A Village in the Valley 
specific region? and b) How can the enabling infrastructure we are pursuing empower users?

Over the course of the paper, we will first give an overview of the relevant literature regarding the concept of computer clubs and socio-technical initiatives for their development. This underpinned our efforts to develop an enabling infrastructure. We then describe the specific Grounded Design-based ethnographic approach we adopted to study this particular intervention (Wulf et al. 2018). This is followed by our findings regarding the planning, facilitation, appropriation and challenges associated with setting up the computer clubs. At first, these were primarily used for informal learning sessions, but they came to form the backbone of the socio-technical enabling infrastructure. In our discussion, we reflect upon our endeavour and its implications for similar initiatives and discourses.

\section{Research Setting}

The Kingdom of Morocco is a constitutional monarchy with an elected parliament. The current Moroccan royal family belongs to the Alawite Dynasty, which first came to power in the seventeenth century. The country was divided into French and Spanish protectorates in 1912, but, after a protracted struggle, it regained its independence in 1956 and was established as a constitutional monarchy in 1957 with Mohammed V being proclaimed king (Pennell 2003).

In 2018, with a total population of 34.8 million, Morocco ranked the fifth largest country in the Middle East and North Africa (MENA) (OECD 2018, 34). Next to Rabat, its capital, the other most important economic and tourist centres are Fez, Casablanca, Marrakesh, Tanger, Essaouira and Agadir. One of the biggest issues confronting the country is its persistently high unemployment rate, which particularly affects females and younger people (World Bank Group 2018, 28). This remains the case despite many improvements over the last few years (World Bank Group 2018, 1). A lack of trust in politics and institutions has led to protests, seeking greater equality, transparency and better efficiency in government services (World Bank Group 2018, 48).

Arabs and Imazighen ${ }^{1}$ make up $99.1 \%$ of the Moroccan population (Menz 2010). Considered the indigenous people of North Africa, Imazighen are said to have been living in this region for several thousand years and adhere to Islamic beliefs. The Imazighen have therefore always been an important part of Morocco's history and have become increasingly important for public displays of the country's culture and identity. There have been challenges to an established dichotomy between 'Arabs' and 'Imazighen', where Arabs have been associated with wealth and urban living, while Imazighen have been considered the poorer, primarily rural population. Thus,

\footnotetext{
${ }^{1}$ In this paper we use the terms, Amazigh“ (singular) and, Imazighen'(plural) as used by activists in the linguistic and cultural rights movement, instead of the term, Berber'which has an external origin. There is, however, an ongoing discussion about the use and connotations of these terms.
} 
Crawford has noted that Imazighen 'do not only exist in rural areas, but in all of Morocco's cities and all social classes' (Crawford 2008). In recent years, linguistic and cultural rights movements have grown that aim to revive and promote the Amazigh cultural heritage. Their main language, Tamazight, was not recognized as an official language until 2011 (Canada: Immigration and Refugee Boardof Canada 2000).

It remains a fact, however, that there is a large contrast between the urban and rural areas in Morocco (The World Bank 2021b), with the more remote mountainous regions mostly lacking basic infrastructure or medical care and having limited access to job and educational opportunities (The World Bank 2021a, 4), and these regions are primarily inhabited by Imazighen. Around $60 \%$ of women (countrywide) cannot read or write (NationMaster 2019). While official numbers for female Imazighen are not available, in (informal) conversations with inhabitants of the valley we work in, it was stated that the majority of female Imazighen over 18 are illiterate (Dodson et al. 2013; Slawson 2016). Unlike the rural male Amazigh population, most of the women also primarily speak Tamazight and have only rudimentary Moroccan Arabic at best (Hoffman 2008).

Our field work, especially in our first two trips, revealed a number of characteristics that would help us to better understand the local conditions and later on these shaped our endeavour. The valley in the High Atlas where the intervention is still taking place is divided into six smaller villages and has a total of around 10.000 inhabitants. According to oral tradition, the oldest village was founded by the end of the fourteenth century. The whole region has a rich socio-cultural history and a significant religious tradition. Most of the local household economies are based on agriculture and pastoralism, including transhumance, with people moving their livestock seasonally to pastures on the higher plateaus surrounding the valley. In addition, the men may sometimes work in the local administration, construction or tourism. Some have also left the valley as labour migrants to bigger cities.

Over the past two decades, the region has been subject to profound change. Since the mid-2000s important infrastructural improvements and developments have taken place. Households in the principal villages now have access to running water and electricity. With the establishment of electricity, the use of satellite television has spread. The major road to and from the valley has been surfaced and a small health centre including two nurses and three ambulances has been introduced. A big telecommunication company now provides an LTE network throughout the valley. However, one of the main villages still cannot be reached by car, but only on foot or with pack animals. A new school was built five years ago, which - as an informant told us - is a major improvement for the region because this now allows children to get a primary and middle school education. As a consequence, an increasing number of people from more remote settlements have decided to settle in the main villages.

The above transformations have been accompanied by increasing NGO activity in the valley. Many of these are local associations or community-based organizations with a variety of different purposes or responsibilities, but most are focused on agriculture, tourism or cultural heritage. One very active community work 
association started in cooperation with a French association at the beginning of the 2000s. It later continued its work independently, focusing on communal infrastructure projects and has the broad support of the local population because it consists only of local people. In 2009, an American NGO started to work with the local population and the aforementioned NGO to re-establish an interest in cultural heritage and to further improve local living conditions. To achieve this goal, they not only undertook fundraising but also invited students from the US to work with the inhabitants on different sustainable projects such as garbage incineration.

\section{State of the Art}

There are three main bodies of literature relevant to the study we are presenting here. One relates to the overall research interest in enabling infrastructures and appropriation. The second is centred around (educational) socio-technical initiatives for communities in transition, within which $\mathrm{HCI}$ and $\mathrm{CSCW}$ has played a significant role. The other relates more specifically to computer clubs, the origins of the idea and how it has been drawn upon in various contexts. In addition, some anthropological literature about Morocco, Imazighen and media technology was important for our intervention, so, we shall very briefly survey some of the most pertinent findings to come from that literature as well.

\subsection{Appropriation and Enabling Infrastructures}

Appropriation, as an independent concept beyond customisation and use, has been a topic of interest in HCI and CSCW research for some time (Orlikowski 1992; Dourish 2003; Draxler et al. 2012; Tchounikine 2017). In the early nineties, Orlikowski (1992) suggested that the 'organizational introduction of groupware will interact with cognitive and structural elements, and that these elements will have significant implications for the adoption, understanding, and early use of the technology' (Orlikowski 1992, 367). She elaborated on the impact that such interventions can have on practices in work settings: 'When an organization deploys a new technology with an intent to make substantial changes in business processes, people's technological frames and the organization's work practices will likely require substantial change' (Orlikowski 1992, 368).

Dourish (2003) later argued that appropriation relates to 'the way in which technologies are adopted, adapted and incorporated into working practice. This might involve customisation in the traditional sense (that is, the explicit reconfiguration of the technology in order to suit local needs), but it might also simply involve making use of the technology for purposes beyond those for which it was originally designed, or to serve new ends' (Dourish 2003, 467). He further claimed that 'appropriation lies at the intersection of technical design and social practice' (Dourish 2003, 467) and that making this the subject of investigation provides opportunities to combine design research with sociological studies. 
More recently, Quiñones (2014) has stressed the importance of 'shepherds': people who formally and informally give support in cultivating practices and sensemaking around technology, for both target users and unanticipated users (Quinones 2014, 305). Shepherding or guiding others in using technology has proven beneficial for successful appropriation and, therefore, appropriation in the context of ICT interventions in workplaces (Rechberg and Syed 2014). Draxler et al. (2012) can be understood as 'a social and collaborative activity' (Draxler et al. 2012, 2835). When seeking to find design principles that approach IT design more holistically, Draxler et al. elaborated upon this by redefining appropriation as 'an entangled, cooperative process of searching, becoming aware, installing, configuring and learning how to use new tools' (Draxler et al. 2012, 2835). When explicitly designing for collaborative appropriation, they suggested that support mechanisms 'should exploit this diversity, as it allows people to learn from each other. In particular, it should support the situated and social nature of appropriation in the context of modifying tools and learning new features in interaction with colleagues' (Draxler et al. 2012, 2835). Their definition is grounded in an understanding of appropriation as 'the social process of incorporating objects into one's life, including changes to the objects caused by modes of using it' (Draxler et al. 2012, 2836).

According to the definitions outlined above, we can consider appropriation to be an ongoing cyclic process of adapting technology to contexts as well as adapting oneself to changes made by implementing technology. This, however, has also been described elsewhere as co-evolution or mutual adaptation. Leonard (2011) suggests 'that initial implementation of technical innovations is best viewed as a process of mutual adaptation i.e., the re-invention of the technology and the simultaneous adaptation of the organization. Such mutual adaptation was found to be associated with successful implementation in a study of educational innovations among school districts' (Leonard 2011, 253). With regard to the implementation of IT systems, she states: 'Technology transfer requires [...] continuous, ongoing dedication to the process of change and the conscious management of mutual adaptation because the technology will never exactly fit the user environment' (Leonard 2011, 265).

Recently, Tchounikine (2017) has presented a theoretical framework on how to design for appropriation that has as its goal 'empowering users to 'continue software design in use" (Tchounikine 2017, 158). In his view, "According to the adopted perspective, empowering users to continue design in use corresponds to different realities: using adapted means of analysis to inform designers and help them to match users' needs and usages, allowing a community to make a system evolve [...]' (Tchounikine 2017, 177). The importance of creating a 'Tailoring Culture' (1990) like this was first addressed by MacLean et al. (1990). In essence, this refers to a community that has been invited to, and that is willing to, adjust and make modifications in whatever way its members see fit, so as to enable everyone involved to make better use of the system. 
Tightly related to the preceding discussion of appropriation is the notion of an enabling infrastructure. An enabling infrastructure provides, as the term implies, an infrastructure that enables users to work or create something in an independent or collaborative manner. The term is largely used in the field of information systems and development.

In this regard, Johanson and Fox (2002) have presented what they call an 'Event Heap', which is an enabling infrastructure for interactive workspaces that allows multi-user interaction through features such as bulletin boards. The focus, here, lies on simultaneous interaction, flexibility and failure tolerance. According to Blecker and Graf (2003), mass customization for multi-agent systems requires a high level of reconfigurability and flexibility for it to constitute an enabling infrastructure. For them, 'enabling means that an infrastructure allows or supports implementing business strategies or concepts' (Blecker and Graf 2003, 14) and an enabling infrastructure 'has therefore to offer prerequisites for sustained realization of mass customization' (Blecker and Graf 2003, 15).

Mitleton-Kelly and Papaefthimiou (2000) have argued for the benefits of an enabling infrastructure when motivating co-evolution between the fields of business and information systems, because it 'enable[s] the emergence of new ways of working'. They consider the key enabling conditions to be: networking and trust through monthly meetings; autonomy of the project manager, supported by a senior manager; stability or sufficient continuity of the project; and an interpreter who can mediate the dialogue between the two domains. They conclude that an enabling infrastructure 'provides the conditions for self-organisation, emergence and exploration of the space of possibilities' (Mitleton-Kelly and Papaefthimiou 2000, 178).

Bridging between this discourse and our own particular case, we consider an intervention that establishes a physical and tangible technology-equipped space to be an enabling infrastructure. This space provides for the liberty and flexibility of individuals and 'mass' or community customization and individual and multi-party use to meet individual and community needs. The space is a technological and spatial infrastructure that not only allows for, but invites co-evolution between visitors, users and the people in charge.

\subsection{Educational Socio-Technical Interventions for and with Communities in Transition and ICT4D}

There is an enormous range of ICT-based educational initiatives in the field of development cooperation, and it would be impossible to review all of them for this paper. Here, we focus on selected relevant studies about communities confronted with a need to deal with radical change. This spans both refugees and migrants, people dealing with city redevelopment, communities seeking to re-build after natural disasters and conflicts, and communities in rural areas that are having to accommodate economic, political, social and technological change. 
An emerging direction of research in Human-Computer-Interaction (HCI) is ICT for Development (ICT4D). This movement seeks to bridge digital divides and support local economies through the use of technology. The ICT4D literature provides a number of valuable insights, especially when it comes to the problems confronting rural areas. Heeks (2008) has examined the different stages of ICT4D over time and how the need for technologies and approaches has evolved. In his view, telecentres played the major role in ICT4D 1.0 in the 1980s and 1990s, mainly in North American and European research. These centres could provide internetconnected computers and could therefore be installed quickly and easily almost anywhere. This was useful when working in rural areas. However, internet access and electricity were required to run such initiatives. In addition, people had to come to the telecentres because they were effectively stationary set-ups (Heeks 2008). Providing ICT as means to foster local technology uptake and entrepreneurship in communities was later the main focus of technology hubs, which opened in several countries in Africa.

To successfully implement an intervention, different factors and barriers play a role. These include: unequal access to interactive digital devices such as smartphones (mobile divide) because of the high cost of mobile phones and broadband connections; insufficient ICT skills among teachers and learners; and the English language bias on the Internet, which people in rural areas can often not understand. In addition, there are cultural and social barriers in some societies that prevent women from gaining access to public spaces for Internet access and from owning mobile phones (Chinapah and Odero 2016). Zegura and Grinter (2013) examined factors in lowresource settings and highlighted the importance of having an individual local party as a 'community manager' (Zegura and Grinter 2013).

Tongia and Subrahamanian (2006) have proposed a new model for ICT4D endeavours because many such projects fail. There are a number of reasons for this, including a mismatch between goals and incentives. They also argue that

'bringing a computer into poor, rural areas is unlikely to help education significantly, at least not on its own. But such projects garner significant media attention and funding. The real space of development is vast, spanning infrastructure, food, healthcare, education, economic growth/jobs, governance, and empowerment.' (Tongia and Subrahmanian 2006, 244)

They stress the necessity of including users early in the design process, to ensure that solutions are not externally imposed because these will inevitably fail in the longer term. Here, researchers need to consider the whole ecosystem with all the relevant stakeholders (e.g., the targeted population, NGOs, academics, etc.) to ensure the success of the project. When it comes to sustainability, a particular issue is that 'funding groups often have statutory or charter constraints, and they often seek 
'visible solutions' that limit longer-term ICT4D solutions that are not readily deployable' (Tongia and Subrahmanian 2006, 244).

Easterly has argued that (the absence of) incentives is one of the main reasons why projects fail, with externally imposed alternatives being predisposed to failure (Easterly 2002). Toyama (2015) criticizes technology-centred approaches toward solving issues in countries undergoing transition and argues that technology can only amplify existing human capacity and intent, rather than serve as an effective substitute for them. Thus, approaches to address issues should always be human-centred.

Winschiers-Theophilus et al. (2010) discuss the importance of including users in ICT4D efforts to create sustainable initiatives, especially when it comes to different socio-cultural values and rules. Respecting hierarchies and power structures plays an important part. Botes and van Rensburg (2000) present nine obstacles and twelve guidelines for participation in development projects, starting with the paternalistic stance of some outsiders, who consider themselves as experts and therefore don't facilitate, but rather manipulate development processes. The twelve recommendations include having awareness and respect for the local culture, being good facilitators and empowering the local community. They sum up by stating:

'Although successful participation is very elusive, these guidelines serve as a developmental ethical code of conduct to bringing disparate groups together for the real intention and praxis of participatory development.' (Botes and van Rensburg 2000, 54)

One of the few studies that has engaged directly with ICT use in the context of Amazigh activism was conducted by Dodson et al. (2013). Here, they endeavoured to understand the character of mobile phone use among low-literate AmazighMuslim women in this predominantly oral language community in order to understand the group's mobile phone usage (Dodson et al. 2013). The results indicate that there were social, technical and cultural barriers for the participating females to overcome. Pruneau et al. (2018) have sought to address environmental issues through the use of ICT in remote villages in Morocco. In this case, issues relating to drinking water and floods were tackled together with females from the area by using Facebook as a vehicle for Design Thinking. The participants used all the available functions of Facebook (posts, photos, videos, commenting, likes, etc.) to share views about the floods and their consequences. They further found that the females they worked with not only felt more comfortable using Facebook, but that they also created a strong network that wanted to continue to share problem-solving ideas in this way. They came to the conclusion that being able to express thoughts and feel heard and understood was one of the key motivators. Here, ICT was directly used to address an issue the women had faced many times before without any technological component (Pruneau et al. 2018). 
The research presented in this paper fits into this larger body of research exploring the influence of ICT on education in communities in transition and ICT4D. Simultaneously, the research project, on which this paper is based, goes beyond this framework by making interdisciplinarity (academic collaboration between socioinformatics and anthropology) and transdisciplinarity (local cooperation with an NGO) the starting point for its own intervention and conceptual orientation. Additionally, this body of literature made it possible to deepen knowledge about Morocco's culture, religion and context for fieldwork more generally (Geertz 1977; Eickelman 1981; Rabinow 2007), along with specific culturally grounded power relations and their consequences for politics (Hammoudi 1997). More importantly, they enabled both a historical analysis of the socio-political organization of the region (Gellner 1969) and fundamental understanding about Amazigh everyday life in relation to processes of globalization and economic integration (Crawford 2008; Hoffman 2008) as well as about Amazigh cultural and political identity vis-àvis the state (Crawford and Hoffman 2000; Pfeifer 2011). Only in this way has it been possible to grasp the extent of the radical changes, as well as their historical and socio-cultural implications, that the socio-technical restructuring of the region is bringing into place.

One unique aspect of our research lies in the fact that we closely cooperated with a local NGO and worked within a region in the High Atlas that is undergoing particularly profound change, brought about by better access to the valley through newly built roads, Internet access, increasing tourism, and a broader push to greater political participation amongst the Imazighen in Morocco. The close interaction and working relationship we established with cooperation partners on the ground thus facilitated an ongoing, critical scrutiny of the intervention itself, through which we also became enactors of change. In addition, the project's methodological focus on fully involving local people from the beginning and understanding local conditions, has contributed to the ways in which the study has continued to unfold.

\subsection{Computer Clubs}

A computer club is an open space for participants to work together or alone on personally meaningful projects. The computer club concept has its origins in the computer clubhouse approach established in Boston in 1993 (Resnick et al. 1998). The concept of a computer clubhouse $(\mathrm{CCH})$ was aimed at teenagers in the US coming from lower socio-economic and educational backgrounds. The original clubhouses were built around the idea that children and young adults could learn by designing and building personally meaningful artefacts. The pedagogical concept was derived from a constructivist learning paradigm (Papert 1980). The clubhouse model has grown to a worldwide network of over 100 community centres across 20 countries (more details can be found in (Resnick et al. 1998; Michalchik et al. 2008; Kafai et al. 2009)). 
Over the last decade, six computer clubs have been opened in different cities in Germany. Whilst the underlying concept was inspired by the computer clubhouse idea, it is important to note that it has followed a different approach by focusing on cross-cultural and intergenerational interaction amongst its participants, while working on ICT-related projects. Three of the clubs were established in school contexts, the others in social institutions, with a strong focus on migrants and refugees. These intercultural learning environments were built to foster learning, cross-cultural understanding, respect in culturally and socially diverse neighbourhoods, and to provide access to ICT and other related technologies, such as 3D printers and etextiles that would otherwise be difficult for the local people to obtain (Stevens et al. 2005; Schubert et al. 2011; Aal et al. 2015; Rode et al. 2015).

Participants generally meet once every week and conduct various projects by using technology to varying degrees according to their need (Rode et al. 2015). These projects range from creating games using Scratch (Maloney et al. 2010), 3Dprinting (Stickel et al. 2015), to upcycling projects using garbage. In one computer club in Dortmund targeted at (mainly) female adult migrants, different topics regarding integration in Germany also came up during the computer club sessions (e.g., writing CVs, guidelines on how to find an apartment, or learning German).

In a second step, two computer clubs were founded in Palestinian refugee camps in 2012. These refugee camps were established in 1949, after the state of Israel was founded. Since then, they have been receiving humanitarian services from the United Nations Relief and Works Agency (UNWRA) and other NGOs. However, conditions of isolation, exclusion and poverty amongst the population living in these refugee camps remain ubiquitous. The club in question is part of a children's centre in one of the refugee camps. Every week, (student) volunteers conduct sessions with the children and offer insights into life beyond the camp for its inhabitants (Aal et al. 2014; Aal et al. 2015; Yerousis et al. 2015; Aal et al. 2016; Aal, Rüller, et al. 2018). By following this approach, many insights have been gained with regard to how to establish such an infrastructure. These include involving local stakeholders and future participants from the very beginning and co-developing the infrastructure in a mutual partnership; providing an added value for the participants; and undertaking projects that can be related to the local environment and context (Schubert et al. 2011).

The computer club concept aims to empower participants by encouraging them to work with technology in a more productive and less consumptive way. It should be mentioned that these spaces don't advertise themselves as 'learning spaces' in terms of being an alternative to schooling. The idea is to 'invite' the participants to see and understand computers and technology as useful tools that can be integrated into their everyday lives. 


\section{Methodologies}

\subsection{Methodological Approaches - Participatory Action Research Using a Grounded Design Framework}

The main methodological framing of this research project was based on a participatory action research approach (PAR) (Kemmis and McTaggart 2005), but with the scope extended to incorporate elements of meta-research (Wulf et al. 2018). As a feature of our involvement in the intervention, we tried to understand the local situation, infrastructure, problems and perspective of the various actors. We primarily used observational, qualitative methods, which were complemented by informal interviews, or, to be more precise, conversations, which could not be easily recorded and therefore were written down afterwards. Although it was and still is known in the valley that we are conducting research and asking questions when out in the field, turning informal conversations into formal, recorded interviews would not have been appropriate. As we were told by our cooperation partners and others we met in the valley, people in Morocco are often sceptical about 'being questioned', whether it is about a sensitive topic or something seemingly casual. They are also aware that people who are closely collaborating with the country's secret service are present among them and reporting on a daily or weekly basis about the situation in the village. This impeded our fieldwork, especially in the beginning before we had a reputation among the valley inhabitants. The presence of a political threat was identified by Lee (1993) as one of three issues that create a concern about sensitivity (the other two are private matters such as sexuality, and issues that if revealed might cause stigmatization or be considered indicative of illegal behavior) (Lee 1993). In addition, the access to possible interviewees was limited, since only a few locals could speak English, so we often relied on our partners from the NGO. However, this meant that we often didn't fully understand the situation and whether the interviewee was telling us the full truth.

In principle, the project followed a Grounded Design approach, a framework developed by Rohde et al. (2016) that attempts to overstep the typical 'design-centred' perspective often encountered in IS research. Here, IT development tends to ignore the 'self-referential' or reflexive character of design interventions, where 'appropriating an IT artifact for use changes the very social practices for which the artifact had originally been designed' (op. cit.). Whilst acknowledging that design policies have a technical aspect that can include 'artificial, formal schemes or materialized functions', Grounded Design views IT systems as socio-technical systems that require a holistic view to fully grasp their meaningfulness in use. In its original conception, Grounded Design focused upon emergent changes in social practices that were a result of appropriating and using IT artefacts (op. cit.). Here, we extend upon 
this focus on specific IT artefacts to incorporate an ICT-based enabling infrastructure, i.e., a computer club.

In formal terms, Grounded Design builds upon Multi-grounded Design (Goldkuhl and Lind 2010) and Soft Design Science Methodology (Baskerville et al. 2009), but differs in its recognition of the uniquely local character of the contingencies that shape the design and appropriation process. As noted by Randall (2018), 'whatever design process we engage in, the process of appropriation may, to a degree, be independent of it' (Randall 2018). Properly understanding the local contingencies necessitates obtaining large amounts of qualitative data and, for this reason, Grounded Design is often associated with the notion of Design Case Studies (Wulf et al. 2011; Wulf et al. 2018). Thus, the framework proposed by Rohde et al. (2016) explicitly incorporates Design Case Studies in its formulation. The specific research process is detailed in Table 1:

To pursue the above approach in this particular project, all of the project members visited the valley to get a sense of the local conditions and overall situation, find partners and, eventually, establish a computer club. Each stay was used to learn more about the valley and its inhabitants. Informal interviews and conversations with the inhabitants were conducted and several hiking trips were undertaken to the different villages and plateaus to get further insight into the variety of practices and concerns making up daily life in the valley.

Table 1. The Grounded Design Research Process (extracted from Rohde et al. (2017))

\begin{tabular}{|c|c|}
\hline GD Principle & Research process guideline \\
\hline $\begin{array}{l}\text { Pre-study/Context } \\
\text { study }\end{array}$ & $\begin{array}{l}\text { Start project with an ethnographic study of existing social practices: } \\
\text { - Create a shared understanding of the problematic situation. } \\
\text { - Establish communication schemes for collaboration between researchers and } \\
\text { practitioners. } \\
\text { - Reflect on and explicitly document the results. }\end{array}$ \\
\hline $\begin{array}{l}\text { Working on the } \\
\text { artifact }\end{array}$ & $\begin{array}{l}\text { Designing and implementing the artifact's functions: } \\
\text { - What could work in the problematic situation as we see it at present? } \\
\text { - Reflect on and explicitly document the results. }\end{array}$ \\
\hline $\begin{array}{l}\text { Working with the } \\
\text { artifact }\end{array}$ & $\begin{array}{l}\text { Appropriating newly generated functions of the artifact and evaluationg their } \\
\text { usefulness in a restructured practice: } \\
\text { - How and how well do the artifact functions work in context? } \\
\text { - Reflect on and explicitly document the results. }\end{array}$ \\
\hline $\begin{array}{l}\text { Building the } \\
\text { knowledge base }\end{array}$ & $\begin{array}{l}\text { Reflecting on the whole process through conceptual reconstruction on the } \\
\text { basis of documented intermediate results explaning: } \\
\text { - Why is it working? } \\
\text { This delivers a comprehensive design case study describing the original social } \\
\text { practices, the design discourse, the design options considered, the } \\
\text { appropriation process, the usability and efficacy of the artifacts' functions } \\
\text { and the emerging new social practices - paying specific attention to the } \\
\text { analytical aspects of signification, domination and legitimation as basic } \\
\text { components of the knowledge base. }\end{array}$ \\
\hline
\end{tabular}


In total, the first two authors spent 16 weeks at the field site. In addition, one of the authors, an anthropologist, stayed in the field for nearly a year in order to conduct media-focused ethnographic fieldwork. He stayed with a family in the main village and participated in their everyday activities, routines, and social practices. He also followed closely the workings and organization of the cooperating partners' community projects and tourism programs by, for example, joining tourist groups and guides on their trips or attending intercultural workshops. On the basis of this rich combination of ethnographic methods - participant observation, narrative interviews, an extended stay - and by learning to communicate in Moroccan Arabic and Tamazight, it was possible to gain an understanding of the role and use of media technology in the valley in general. Having conducted the initial investigations and entered into negotiation with local people to identify an appropriate way to proceed with our intervention, a computer club was opened up in the valley in April 2017. We followed this with a series of workshops spread over two weeks to ensure that the computer club could continue to be run by local people in a sustainable fashion. A further 3-week visit was then undertaken in July 2018 to assess how the computer club was being appropriated by the locals. Across every phase, field notes were written every evening to capture experiences and impressions of the day and how they related to various topics e.g., the distribution of political power, gender issues and ICT usage.

\section{Pre-Study Design \& Appropriation}

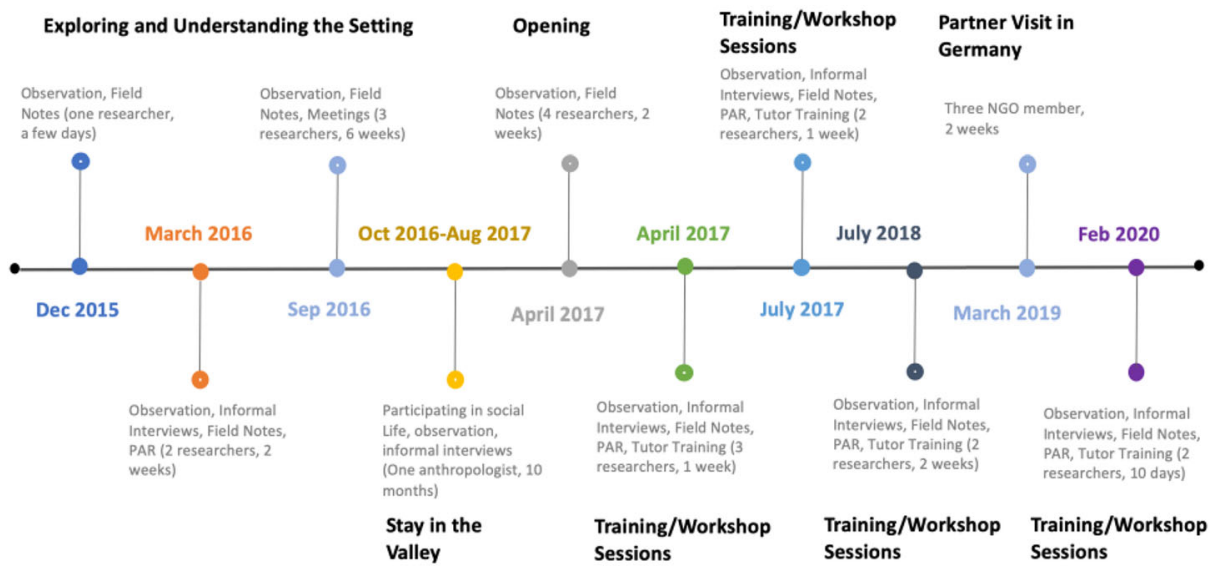

Fig. 3. Timeline of the (field) visits 


\subsection{Field Visits}

To be able to set up and conduct the intervention successfully, the socio-informatics researchers undertook a total of eight field visits (see overview Fig. 3). One of the authors came to the valley for the first time in late 2015 and stayed in a local guesthouse. In March 2016 two other authors were on site and stayed in the same guesthouse. In August 2016 we undertook another visit and one of the authors was in the valley for six weeks to advance the planning of the cooperation. Other authors also joined in the process and were involved in the ongoing negotiations. At the end of this visit, a contract for the cooperation was signed and the second author stayed for a language course in Morocco. This extended visit, during which some early workshops were carried out, was foundational for building a good basis of trust. It allowed for various expectations to be discussed and tackled transparently and productively. This visit also marked the start of the anthropologist's fieldwork, who then stayed in Morocco for almost 12 months, until October 2017, and again in the autumn of 2018, learning the Moroccan Arabic dialect and the local Tamazight language. The opening of the physical space for the computer club took place in April 2017, at which point other members of the project team also got involved to bring hardware and software into the valley. Workshops with and for the computer club tutors were held as well. Two months later one of the principal authors brought in additional technology and further training was conducted for the tutors. In July 2018, we paid another visit to Morocco and looked into how the space and technology was currently perceived and being appropriated by the local inhabitants. In the meantime, the tutors continued to work with the technology and carry out new projects with the participants.

Alongside of our local efforts, we were also keen to facilitate reciprocal visits of our Moroccan partners to Germany. An initial visit of the Moroccans to Germany planned for 2017 had to be cancelled because of problems with the visa process. However, in March 2019 our project partners were able to accept our invitation and visit us for the first time. The main goal was to give them added insight into our computer club approach and the kind of research we were conducting. We therefore organized workshop sessions, aimed at mutual inspiration on how to further develop the project in Morocco. By inviting them to different computer clubs in Germany, we were able to show them the variety of forms computer clubs could take in terms of participants and projects. We also wanted to highlight our own role in the clubs apart from doing research, we are tutors as well. In this way, we hoped to improve the current power dynamics that cooperation between actors from the Global North and South necessarily entail (see (Holdermann and Aal 2019)) and to create a more trustful and open relationship. Our recurrent field visits and existing transparent forms of communication had helped us to identify changing expectations and challenging contradictions (see part 5), but we wanted to further enhance the sense of shared effort and cooperation. 
In 2020, the anthropologist and two socio-informatics researchers visited the valley for ten days. After almost one year of no face-to-face meetings, we were curious as to how the space had changed and what activities were taking place with what technology. Since our last meeting, the NGO had hired a female tutor who was conducting computer club sessions and activities in the space. During this visit, a workshop series with children and older females was conducted, targeting storytelling through photographs of personal artefacts and other narratives.

\subsection{Data Analysis}

The findings, notes and documentation were subsequently analysed using qualitative content analysis (see e.g. (Schreier 2014)). Here we followed Mayring (2000), who promotes qualitative content analysis 'as an approach of empirical, methodological controlled analysis of texts within their context of communication, following content analytical rules and step by step models, without rash quantification'. Additionally, the analysis was undertaken not only within the project team but also with colleagues who had not been immersed in the field. We also took care to send multiple different researchers and students into the field, to ensure a broader perspective and to actively offset any possible individual researcher bias.

The qualitative content analysis of the data yielded seven main themes that drive the organization of the findings below. These are brought together under the following headings: Understanding the local situation: Stakeholders, interests and power relations; Establishing a framework for cooperation; Forging cooperation; Opening the computer club; Workshops; Training of the tutors. Note that these are formulated around our interest in providing an enabling infrastructure that can be appropriated by the local stakeholders, so that they can proceed with developing and shaping the computer club according to their own interests. Appropriation of the computer club for educational support, etc. by the inhabitants of the valley was not our principal topic and we have retained a certain distance from acquiring data relating to this, considering it rather the province of our local partners. The lessons in this paper are therefore primarily directed to others who might attempt to do something similar. These will mostly be parties like ourselves who are interested in pursuing some kind of computer club-based intervention and other designers (see also (Randall 2018) on this point). So, while there will be inevitable differences across such projects, there will also be a shared orientation to the provision of some kind of enabling infrastructure. Thus, beyond the initial goal of providing an enabling infrastructure, the focus in our work has been upon generating findings that provide learning for others seeking to do the same. The initiating parties in such projects will frequently not be local, even if local stakeholders should always be involved and the ultimate point is to enable local people to undertake further development of these kinds of resources for themselves. This can be seen to resonate strongly with the use of Design Case Studies in Grounded Design (Rohde, Brödner, et al. 2016; Wulf et al. 2018), where a key objective is to provide insights that can be drawn upon across projects, as well as within them. 


\section{Findings from the Intervention Process - Establishing and Appropriating Infrastructure}

The intervention in the High Atlas was initially planned to span a period of four years, due to the nature of the project funding. These four years were intended to include the exploration, setting up of the enabling infrastructure, professionalization of the coordinators and tutors, and a first evaluation of the entire intervention, as well as examination of the particular appropriation processes. After this first phase, we wanted to look at ways of continuing the project and, thus, the extending the cooperatively created structures. In May 2020, we were informed that we would receive financial support for a further three and a half years, until the end of 2023. This section presents findings and results related to different dimensions and aspects of the fieldwork conducted during the first four and a half years. Along the way, we will be focusing on the multiple challenges we had to face and the conditions we had to consider with regard to setting up a 'physical' enabling infrastructure and how different forms of appropriation were manifest, and amongst whom.

\subsection{Understanding the Local Situation: Stakeholders, Interest, Power Relations}

That the local situation was complex and perhaps even more complicated than initially expected, became clear right from the start, especially after the first exploratory visit in 2016. In order to create a sustainable intervention and establish some kind of enabling infrastructure, without causing conflicts, but enabling the various interests of the potential partners' to be properly acknowledged, we had to pay close attention to the political organization and prevalent power structures already present in this specific socio-economic context. On the one hand, we had to consider carefully the historical, political and religious background of the region. On the other hand, we had to get a good idea of the peoples' everyday practices in situ and how they instantiated particular orientations and concerns. Repeated and extensive (media-related) ethnographic fieldwork as well as the consultation of regional anthropological studies and broader social science literature proved essential.

Consideration of this body of literature was indispensable in that it, first, enabled a historical comparison of the complex cultural forms in play and thus allowed us to grasp the overall transformation of longstanding forms of socio-political organization in detail. Secondly, it helped us to contextualize our intervention's own objectives with regard to the provision of media technology by recognising how media use and appropriation is culturally embedded and how media technology and their publics are interrelated with political and religious discourses. Media technologies tap into questions of what constitutes a 'good' and desirable life and play a role in people's negotiation of their own identity and biography. This is epitomized, for instance, by the tension between religious tradition and striving to belong to a global middle class (Cohen 2004; Courbage and Todd 2008; Gertel and Hexel 2018). Thirdly, inspection of this literature invited us to reflect on the power relations 
among the involved stakeholders and on how we would necessarily enter and even potentially become a part of these by undertaking an intervention. At the same time, it encouraged us to constantly question our own collaborative practices and helped us to determine and reflect upon our own positionality.

The power relations and political organization in the valley, which could only be properly understood and investigated through extended research stays, are arranged around four distinct, yet intertwined entities. 1) There is an administrative body whose officials are more or less appointed directly by the king. 2.) There is another administrative body with elected representatives. 3.) There is a more traditional form of political organization (taqbilt ${ }^{2}$ and sheikh ${ }^{3}$ ), within which the specific character of Moroccan Islam plays a crucial part. This is of historical importance and is considered part of the culture. 4.) The are the NGOs, with their different projects and interests. These play an important role by occupying a strategic intermediate position between the local community, the administration and their own goals.

With so many different actors and interests on the ground, we feared that working with some stakeholders might lead to scepticism or withdrawal on the part of others who were not able to benefit from our engagement directly. We were perceived as a resource, coming from a university out of the global north and bringing money, technology and expertise. Finding a partner was a challenge in itself. In the valley, there are various and competing stakeholders, including official NGOs and associations, both from the region and from abroad. Often, these are also engaged in tourism in some way, which is the biggest source of income in the region. This only adds to the degree of competition. Negotiating different positions, personal advantages and prior understanding with these groups was particularly important. The distribution of scarce resources can constitute a major source of conflict. Reflecting on our own positionality in relation to this and the potential impact of our intervention was as crucial as keeping in mind that cooperating with our local partners meant strengthening their position. In other words, we wanted to avoid (accidentally) taking sides. During the next stay the authors changed guesthouses and stayed with the leader of a local NGO, which already had a very good reputation. In the following weeks the contact with this NGO was strengthened. Of course, this relationshipbuilding was not one-sided. The conditions and modes of engagement had to be worked out mutually in a processual way. In this particular regard, having the local NGO as a partner helped us to avoid many pitfalls. It enabled us to develop a good basis for communication with all of the different actors involved. At the same time, the NGO's outstanding reputation enhanced belief in our trustworthiness and

\footnotetext{
${ }^{2}$ The concept of 'tribe' and 'tribal society' (which is also an approximation for the emic term taqbilt) is a very prominent and popular notion in social and cultural anthropology, albeit highly contested and largely abandoned as a sociological category today. Yet, it continues to be virtually unavoidable as an ethnographic category on the ground.

${ }^{3}$ The sheikh is the religious and cultural head of the community. He functions as a mediator in case of conflicts between valley inhabitants.
} 
sincerity in advance. We, in turn, acknowledged their expertise and gave them a free hand in how the integration of the enabling infrastructure should and could be geared into the needs and interests of the local context. Having teamed up with the NGO, the whole endeavour became much more open to discussion amongst our partners. Once the NGO was ready to take over the supervision and implementation on-site, we noted a significant advance in the trust we were accorded by the local population. In their eyes, the already very welcome tutoring activities being undertaken by the NGO had been put on an important new footing through this new cooperation and the integration of ICT. It was felt that the local children were now even better able to shape their potential for a successful future through their engagement with technology.

However, this also meant going through recurrent negotiations about our own constraints and competing expectations (see also section 6.2), such as who should be the main initial target group for the enabling infrastructure. The NGO already had a tutoring program in place, aimed at improving school children's education. This provided an excellent interface for combining existing practices with new media technology and the idea of a computer club. The implementation took the form of enabling the tutors to expand their teaching to include ICT and playfully enrich it with project examples especially designed for children.

\subsection{Setting-up the Framework for Cooperation}

In order to mutually create the conditions for effective cooperation, a number of challenges had to be tackled.

Language. The language barrier was one of the most obvious and challenging issues to deal with. The mother tongue and everyday language in the valley is Tamazight. However, language skills are remarkably gendered. While a great number of men also speak the Moroccan Arabic dialect - with varying degrees of expertise - this is far less the case for women. The illiteracy rate among middleaged and older people is rather high as, until relatively recently, schooling was rare in the mountains. Today, children grow up learning Tamazight at home and Modern Standard Arabic in school. In the 6th grade, French is added, and our partner NGO provides some English tutoring after school.

Working together with the local NGO meant we also had support when it came to language - even interpreters. Some of the younger members of the community had studied at university and were reasonably fluent in English, especially those working in tourism. These individuals were crucial in creating a common ground for exchanging ideas and making conversation, especially at the beginning. Bridging the language gap by learning the local language and/or using French and English, brought us closer together as cooperation partners. In either case, we met as learners and had to work out how to communicate.

However, not being able to fully speak to everyone individually in the same depth meant that we had to rely on people's translations and therefore interpretations as 
well as the fact that some people would not necessarily speak their mind in front of their colleagues or bosses.

Expectations. One of the central tenets of our methodological approach and research is that it be participatory in character. This meant that we had to acknowledge that, while 'we' might assume a role as experts for ICT, our cooperation partners obviously held the expertise regarding the adequate appropriation of media technology and the computer club in relation to the cultural context and local needs. We could not therefore say how something should be used or done, but rather had to merely propose ideas and ways of doing. For example, computer clubs in Germany are principally treated as open spaces for anybody who is interested, regardless of their age or motivation. We had a preliminary meeting with the NGO's president $\mathrm{Ahmad}^{4}$, his employee Nabil, who we'd already spent a lot of time with, and the two future tutors, Ibrahim and Basem, to get to know each other and talk about everyone's background, expertise, skills and expectations for what should be happening in the space.

Our cooperation partners found it more appropriate to first tailor the offer specifically to school children and to implement it as part of their educational program. Another way in which our expectations proved to differ concerned the style of teaching or guidance. The coordinators or tutors, who already had some teaching experience themselves, were used to a very teacher-centred format. The original computer club idea was formulated around a learning-by-doing atmosphere, which values collaborative engagement with technology in a 'community of learners', rather than formal teaching. For the future, they formulated their expectations: 'My wish is to connect the mountains to the cities in Morocco; illiterate people can learn to use computers and find new jobs (or find a husband or a wife online).' (Nabil).

As a first target group, we decided to work with children and young teenagers. Our project partners had expressed an urgent need to do this because it fell outside of their regular school education. People from the valley also have high hopes that this generation will be much better educated. For many, this includes a higher level of digital literacy. During meetings with the coordinators and the NGO's president, expectations regarding the project and the future cooperation were discussed. Ibrahim admitted that it is sometimes hard to deliver messages to his students but that computers can make learning more enjoyable for children. Ahmad felt that technology (education) was a huge issue for the NGO's work but that he saw lots of opportunities for the valley's inhabitants (such as being able to address environmental issues and to empower females through technology or e-commerce). Nabil hoped that the space would serve the entire valley, including providing them with a way of finding jobs, future spouses and friends. For everyone in the room, it was important that the space should not be used as an internet or cybercafé. In this region, in particular, they are considered to be rather shady. The shared view was that space

\footnotetext{
${ }^{4}$ All names are pseudonymized.
} 
should serve as a place that would empower people and provide them with opportunities to learn and explore.

Legal matters. Several administrative and legal issues have to be addressed for a long-term cooperation on a transnational scale that involves public institutions like universities. However, NGOs are also subject to national legislation and regulation in order to operate. A prerequisite for wiring funds or sending technological equipment is contracts and official documents. Thus, we had to draft an official cooperation contract between the local NGO and the university. This had to include various 'hard facts' pertaining to the agreed-upon collaboration, i.e.: the duration and amount of financing; guarantees; and declarations of intent. This necessitated the involvement of other potentially more disinterested actors, such as the university's legal department and official bodies in the Moroccan administration.

Organisational matters. Planning and preparing the cooperation also meant finding suitable staff. As our research project was already staffed, this was primarily a task for our project partners. Both sides appointed program managers. On our partner's side, this was someone who was fluent in English and thus well-equipped to communicate with us. It was, however, more difficult to find the right tutors and program coordinators. Initially, this was an additional task that was given to teachers who were already employed within the NGOs' education program, until new potential coordinators could be identified and hired. The NGO was responsible for this process. The two men from the valley who were designated as coordinators were not well-trained in the use of, or familiar with technology. So, before they could start to conduct sessions, they had to acquire a basic understanding of how to use a computer and the associated tools that would be important to support people in the use of the provided infrastructure and, with regard to computer club sessions, participants during their project work. After elaborating on the concept of the computer club, our partners understood the essential role of the tutor as a supporting role model: 'The tutor is not a teacher; he is someone to support the participants and all of us are learning from each other' (Basem). The first workshops with the tutors focused on the basic use of the computer: how to turn it on, what functions were available, how the mouse and keyboard worked, and how to install new software. As it was the first time both tutors had used a laptop (even though one of them had studied at university), this took a lot of time.

\subsection{Physically Forging Cooperation}

Apart from the repeated and extended visits of project members to Morocco, the cooperation took a material form in the infrastructure that was and is necessary to facilitate it. This, too, took effort to forge. A proper building was needed to house the enabling infrastructure and eventually the computer club sessions. In collaboration with another NGO, our local partners were already building a new and bigger association building for schooling and workshop purposes. The timing was excellent and we agreed on integrating 
our endeavour within this structure. The construction was executed by the NGOs own workers and some additional volunteers. In a sense, the building itself epitomizes the NGO's ongoing and successful network of cooperation: the labour force and building materials were provided by the NGO itself; the tiles were sponsored by a partner institution; the furniture was acquired by another affiliated NGO; and the shelves and technology were provided by us. Initially, we had planned to ship the devices, but this turned out to not be feasible. As there were specific regulations concerning the shipping of batteries, only a few private companies would agree to do it. This, however, would have entailed costs that would have made a shipment completely uneconomical. We therefore decided to bring the technology into Morocco ourselves. This, in turn, was not without complications when it came to clearing customs. Initially, we even had to sign a document that obliged us to take a 3D printer back to Germany at the end of our stay and forbade us to officially import it. Administrative delays in the transfer of funds and the delivery of shelving put our joint planning to the test on occasion. It reminded us that cooperation is not only achieved through joint declarations of intent, but above all through continuous reassurance, when even the smallest planning steps fail to proceed as expected. Before even opening the space, we spent a lot of time on simply communicating expectations, visions and concerns.

\subsection{Opening of the Space, Workshops and Training of the Tutors}

The space was officially opened with a kick-off workshop and a big celebration. In a hands-on atmosphere all the various technical devices were spread across several tables. Children and interested adults who had come had the opportunity to try out the ICT themselves. All of the project partners and researchers were available throughout the event and gave joint assistance if necessary, regarding how to use the cameras, tablets or laptops and the various software or apps. Even though it had been announced only two days previously, around 70 people came to the opening, 25 adults and 45 children. Apart from our partners from the NGO, who had also brought their friends, a lot of children, older valley inhabitants, teachers from the school and the sheikh joined to celebrate the event. Our partners brought tea and cookies and squeezed as many people as possible into the room. There were some speeches from the local NGO about our cooperation, the envisioned project and the possible outcome in the future, followed by ad-hoc responses from us with translations. One of our partners encouraged the attending guests to try out the available technology: 'Don't be shy. You can't learn anything when you are shy.' (Nabil).

The following fragment from our field notes illustrates a workshop session that was conducted with the tutors and some participating children (Lena and Karl are two of the authors, while Basem and Omar are the two tutors): 
Lena and Karl meet Basem and Omar to prepare for the workshop. They ask if the kids know how electricity works. [...]

All of them were working on their own designs. There are some sticky LEDs that didn't work that well with copper tape and required pressure to make the LEDs light up. Everyone switched to LEDs with little metal sticks and now they work perfectly. Karl also noticed that the copper tape should be taped on first and the LEDs should be put on top, especially with the sticky LEDs. [...]

15 kids showed up, and the tutors divided them into groups of five. Basem was checking the kids' work, especially when the LEDs wouldn't light up. In 99 percent of the cases, it was because the two lines of tape were touching each other. Also, sometimes there was not enough pressure, especially when they just put the LED on top of the battery. [...]

Ibrahim said this project was a great mix of arts and science. Some kids might think about it from now on whenever they switch on the ceiling light. Others were already talking about the insect that has light on its 'behind'. (Probably a firefly?) [...]

At the end, Omar asked what to do with the creations because the kids would like to take them home and show their families. Lena and Karl were surprised. Karl said it was all theirs, of course they could take it. Karl wrote down the vocabulary relating to the session in English (circuit, copper tape, battery, etc.). Ibrahim then explained and translated, and the kids transferred the English terms to their notebooks or on a piece of paper. [...]

This extract shows how such sessions involved a mixture of hands-on problem solving and educational highlights, pulled out to save for future reference. It also shows how there were initial uncertainties about who 'owned' the materials that were being made available, something that took time to dispel.

In general, the level of ICT literacy and overall access to ICT observed during the opening was rather low. This confirmed the impressions we had gathered prior to the event. Older adults in the valley have only been exposed to television for five to ten years. Even children and young adults were not familiar with the use of computers or tablets. There was only one room with older computers in the entire valley that was used by the local NGO for educational purposes. A few employees in the local administration had access to a computer at work, but most of them had at best only rudimentary IT skills. Only a very small group of wealthier inhabitants possessed a laptop or tablet and knew how to use it. Although an increasingly significant number of older children and adults are using a smartphone on a day-to-day basis, only a few have a detailed understanding of phone or app settings. Even some of the university graduates found it difficult to use the basic functions of a computer 


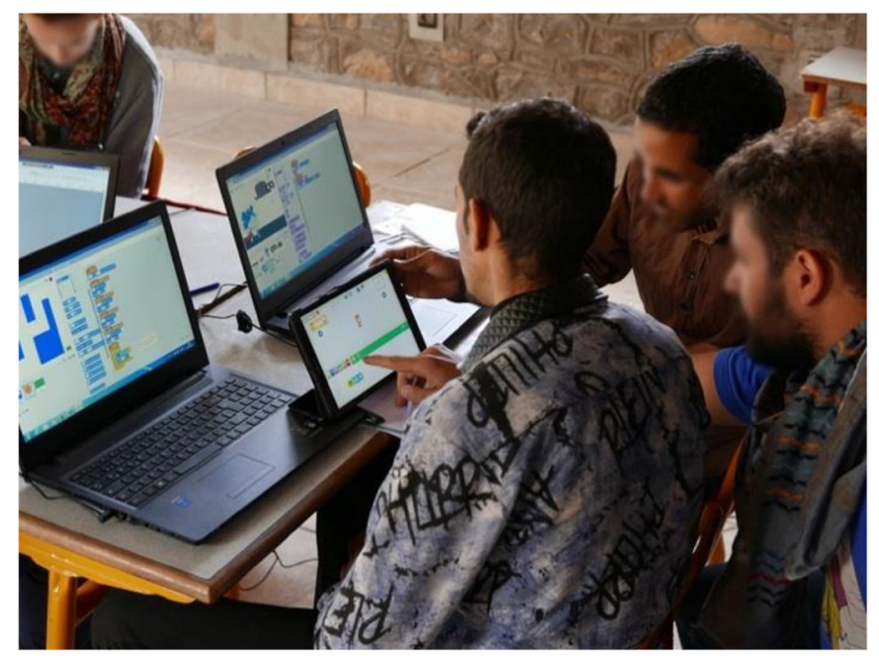

Fig. 4. Training of the Tutors

because they were not using one on a daily basis or had no access (e.g. copyand-paste, right-click, or the coordination required to use a computer mouse). This was also one of the first issues that was encountered during the computer club sessions with children. For the majority of the young participants, it was the first time they had interacted with a laptop or ICT in general. The tutors had to playfully demonstrate what a desktop is, how to use software functions, such as folders, or how to operate input devices such as a keyboard and mouse. In informal interviews with well-connected members of the local NGO, concerns about the use of mobile phones and access to the Internet were raised. From their perspective, young adults were using the Internet only to chat on Facebook or WhatsApp, or to watch videos on YouTube - but not as a tool for education or learning. From what we saw during our trips, technology use amongst (young) adults was, indeed, primarily focused upon communication via social media and video streaming. However, we have had not yet been able to take a closer look at the Internet consumption of children and adolescents. Nonetheless, the children and teenagers who took part in the computer club sessions seemed to be much more interested in creating movies and taking photos - just for themselves.

The authors extended the training with the tutors during each visit through new technologies or the use of new software (see Fig. 4). Here, however, it was important to not only learn technical skills, but to also get a sense of how and where to obtain knowledge and get ideas on your own (e.g. YouTube tutorials). We usually worked with the tutors first thing in the morning, before we conducted a workshop with children about a similar topic in the afternoon, where the tutors were then in charge of applying their newly acquired knowledge. 


\subsection{Unforeseen Appropriation and Consequences}

Once the responsibility to organize daily routines around the enabling infrastructure and to develop ideas, technical skills, and collaborative work are in the hands of local project partners, appropriation is in full swing. From the perspective of those who first conceived the idea for the cooperative project, appropriation meant that the project was finally taking on a life of its own. While the process was evolving, things could happen that were not possible to anticipate beforehand. At the beginning, there were numerous brainstorming sessions and planning meetings between all of the partners involved, which revolved around putting forward ideas and desirable outcomes, and sharing experience. At this point, not all the consequences could be foreseen. In the case of the enabling infrastructure, expressions during these meetings were less about the project itself than about making known one's own expectations or the lines along which you were anticipating or planning.

Perhaps the most profound consequence of this endeavour concerned the staff who were employed as coordinators and tutors. Initially, the established space had been envisioned as a meeting place and hub to interact with ICT and undertake creative project work to tackle everyday problems. This in turn, so it was hoped, would open up new opportunities for the participants, be they educational, professional, or economic. Yet the biggest opportunity throughout the first project phase opened up for the coordinators themselves. Two of them, who had been part of the project team from the start and increasingly gained working experience, were able to make a transition to the necessary formation to become a teacher in a public school. Thus, they were able to use their activity as tutors of the computer club sessions as a springboard for their further professional development. This allowed them to make sure that the teaching profession was the right choice for them and to gain a foothold in the desired field of work because they were not financially dependent on other temporary jobs.

Simultaneously, as they left to follow their new carrier path towards a more highly qualified job, their two positions in the club became vacant. These new vacancies again offered promising opportunities for suitable peers from the community. The position enabled one of the newly employed tutors, who became the main facilitator on the ground soon afterwards, to settle down. He had been working sporadically in the tourism sector in a neighbouring valley. As an only son, with a wide network of relatives and a sense of needing to stay close to the parental home and land, he wanted to stay in the valley, or at least nearby. However, job opportunities are scarce in the valley outside of agro-pastoralist farming and industry is completely absent. This usually means taking on the few temporary jobs or craft activities available locally or migrating seasonally for work to urban centres or major national construction sites - often distant and for many months in a row. Working for the computer club therefore effectively represents something like a professional alternative to labour migration (and to the few prestigious positions in local administration or the school system). As a consequence, after having worked for about a year, the new 


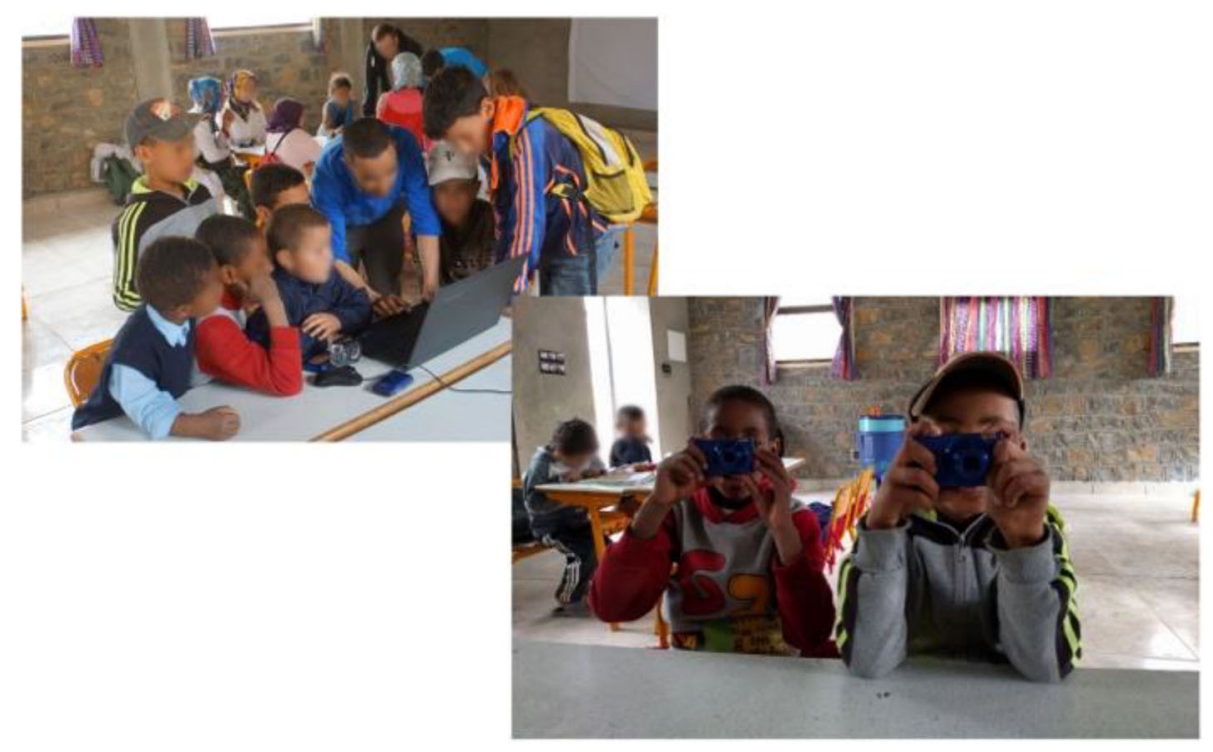

Fig. 5. Computer club session

coordinator had married and built a family home next to his parental house. Of course, this is in no way suggests that this was only possible because of his new occupation. Nevertheless, being able to undertake significant work within the valley, have a regular income and having the security to plan in ways associated with this may certainly contribute to entering the next stage of life. We had not foreseen that our intervention would establish the project as an employer, which makes it even more important to collaboratively and sustainably work for the longer term.

In early 2020, we went back to the valley. It was a year since meeting with our project partners in Germany and one and a half years since we had last been there. Amira, a female tutor (who is married to Basem) was co-tutoring the sessions and appeared to be the main contact for adult women, who were interested in using the space themselves.

The spatial organization of the space had changed drastically. Since its opening in 2017, there had been continuous changes regarding the set-up of the tables and whatever books and other equipment could be found. There were decorations on the walls and projects from previous sessions in the shelves. The entire place looked more comfortable and alive - more like it was serving the purpose of being an enabling infrastructure.

In addition to his duties as a tutor for computer club sessions, Basem is now in charge of the NGO's water management system. He registers the water consumption in all households in the valley and prepares invoices. For this job, he uses the space as an office, he has even set up a desk where he can and deal with all the calculations and paperwork. 


\section{Discussion}

\subsection{Appropriation of the Space and the Computer Club Sessions}

The partners from the NGO have integrated the enabling infrastructure space and the computer club activities into their already tried and trusted concept of tutoring, which is supervised by teachers and trained staff. In order to maintain the viability of the computer club, another employee was hired by the NGO. This is comparable to the German computer clubs that take place in schools, which have a designated teacher who is in charge of the club (Schubert et al. 2011). The tutors in Morocco also had to learn basic skills in order to manage the space and carry out corresponding IT projects, which resonates with recommendations made by Aker et al. (2012) and Zegura and Grinter (2013), who highlight the importance of including local community members as 'managers' (see Fig. 5).

In order to facilitate and increase the acceptance of this kind of intervention by the entire community, our partners needed to be involved right from the start and worked alongside of so as to mutually develop the project. They put the entire endeavour up for discussion in decision-making processes and valley meetings. Although integrating the enabling infrastructure into already existing structures increased the likelihood of sustainability and acceptance, it also implied a need to respect and maintain those existing structures and schedules. In the case of computer club sessions, the opening hours were adapted to existing courses, while the school hours were themselves linked to the activities of tourists who help out as volunteers in the valley. However, the development and management of the computer club and the space in general is and will remain an ongoing process, depending on the people involved and their respective opinions. It is important that all parties, including the NGO, the participants, the visitors and the researchers allow for this ongoing development and exploration of what works best. After all, it is a space for everyone to learn and grow. We've already witnessed several large changes in terms of appropriating the enabling infrastructure as a whole.

One big shift happened when a new tutor took over and was in charge of the space and functioned as a tutor in the computer club sessions. The previous tutor had worked as an elementary teacher in the local school and used the club for additional tutoring, more or less with the use of provided technology. The sessions were therefore mainly structured like school classes and the children had to raise their hands before speaking and were asked to stay seated. During the new tutor's sessions, the children were moving around, exploring the technology and speaking more freely, which is in line with the idea of the open sessions of a computer club (Weibert et al. 2014; Weibert et al. 2015).

Another important shift came in March 2019, when some of our partners took up our invitation to come to Germany to get a better understanding of our research interests and other similar initiatives. During the final meeting, they expressed new ideas they had gained regarding how to operate the club and how to integrate ideas 
other inhabitants had already expressed, such as hiring a female tutor, setting up meetings to teach just women and using the technology for online retail.

\subsection{Competing Expectations}

Let us return to the questions of how a viable enabling infrastructure should work and what it should look like. To be in line with a participatory approach, our local partners were encouraged to shape the space according to their own notions of how it should be set up to meet their own needs. At the same time, 'we', as researchers, had already established computer clubs in a number of different communities (Aal et al. 2014; Yerousis et al. 2015; Aal et al. 2016) and had some ideas regarding how such initiatives should be run properly, the kinds of methods that should be adopted and their scope. However, we explicitly wanted to abstain from a top-down approach. The inherent tension in this is a crucial issue for participatory intervention projects and research under conditions of transnational cooperation in a development context. Fundamentally, there is a need to reconcile the goals of intervention motivated projects with potentially contradictory expectations on the part of one's partners (Zegura and Grinter 2013). Clearly, the cooperation partners' expectations and forms of appropriation are of utmost importance in a participatory endeavour that seeks to evade the ills of paternalism and the reproduction of (colonial) power asymmetries (Irani et al. 2010). At the same time, it is evidently impossible to resolve this tension completely, but any such project has to be implemented productively in a mutually respectful and constantly reflective working relationship. In what follows, we want to illustrate some of our expectations regarding the computer club that were not quite met. These were instances where we had to recalibrate our own normative ideas and discuss how we could realign the process of cooperation in a mutually beneficial way.

Communication. To achieve a good working relationship, it is important to be regularly on-site, talking personally about the current situation, but also planning together. However, in this project, it was difficult to communicate without a common language and direct channel, making us reliant upon the local anthropologist for further insights and assessments of potential impact. For a long period of time, it was unclear whether there would actually be any computer club sessions or what exactly was happening, even when a local 'manager' was employed. The local NGO considered it to be our duty to train the local managers/tutors and give precise instructions on how to handle the computer club sessions, as the ones doing the teaching would be perceived to be the experts. Ideally, though, we wanted to encourage the tutors to train themselves (Ahmed et al. 2015; Ndaiga and Salim 2015). Finding a balance between instructing, guiding and giving the liberty to explore was hard, but important. In the end, the tutors were taught basic skills but were also expected to learn new skills via the Internet.

Workshop design. Although some of the tutors had teaching experience, it was mostly front-of-the-class teaching, without a diverse range of methods. As a result, 
the appropriation of the computer club concept was not initially informed by 'makeroriented' ideas, where tutors and children could come together as a community of learners (see, for instance, (Fisher et al. 2016)). The low levels of ICT literacy amplified this issue to start with. This is something that was also encountered by Pruneau et al. (2018). We anticipated some difficulties due to lack of digital literacy but had to adjust our initial expectations very early. As the future tutors already had many project ideas (e.g., video filming and editing), we assumed they knew the basics of how to use a computer. Mostly, we were mistaken, and they didn't even know how to use text-editing software, not to mention basic functions such as turning a laptop on and off and how to use the input devices (e.g., the mouse, including how to double-click). However, it was not hard to slow down and adjust. Finally, the only real cost here was that we all had to allow more time for the project to get underway.

Reach. In the beginning, the idea was to reach as many interested people as possible, who could then come to the computer club and work on individual projects - and thus create an atmosphere of mutual learning by doing. In this region of the High Atlas, however, it became clear that, because of the gendered nature of the society, women would not attend mixed computer club sessions run by a male tutor. At the same time, the local NGO already had a tutoring program for school children in place and particularly wanted to encourage and support children. So, the question of who was supposed to use the space was answered practically and as our cooperation partners saw fit and it then fell to us to try and include them in the process (Tongia and Subrahmanian 2006). We first geared the computer club sessions towards the children, then integrated them into the existing tutoring program, with the hope that this could be expanded upon in the future.

Internet access. Another expectation was the provision of Internet access in the computer clubs. For us, this was a basic requirement for such an intervention. However, some of the locals found the notion of unfettered Internet access problematic and only agreed to it when it was determined that Internet access would only be made available if the tutors were present in the space. They wanted to make sure that they could control what children did on the Internet and which sites they visited. When it comes to designing an entire project, such concerns need to be taken seriously to create a viable intervention, and ways of proceeding have to be shaped around local values and beliefs (Winschiers-Theophilus et al. 2010). This includes technical and infrastructural provision. Generally, use of the Internet, especially Facebook and WhatsApp, is considered to have the potential to distract from 'important' things, such as learning for school. This was despite the ubiquity of smartphones, as was pointed out by one of the partners (Kingdom of Morocco 2008). Ultimately, we postponed the discussion on this point and, together with the tutors, used cell phones to host hotspots during computer club sessions as a way of providing internet access without needing to install a router. 


\subsection{The Role of Ethnography in CSCW: Implications for Collaborative Socio- Technical Interventions}

What can the CSCW community learn from our case? How does it contribute to $\mathrm{CSCW}$ as a field of research field, particularly with regard to 'physical' enabling infrastructures?

Ethnographic field work is well equipped to take on a role as an approach towards meta-research and extended analysis for socio-technical interventions (Crabtree and Rodden 2002; Räsänen and Nyce 2006; Wulf et al. 2018). Extended field work, staying on the ground and spending time with local partners, is crucial with regard to overcoming language barriers and obtaining trust and acceptance. It can also provide important insights and serve as an intermediary for other research perspectives, especially during the fragile beginning of an intervention, when cooperation is still being established, standards are still being formulated, and processes still have to be worked out. It also helps with navigating between the different actors/stakeholders and their - partially - divergent interests. Some controversies can be put on the table or even made profitable, especially at the beginning, when communication patterns have yet to emerge and trust and transparency have yet to be fully established. In addition, this approach is a more inclusive way of understanding technology, its implementation and its appropriation. Räsänen and Nyce (2006) note that 'anthropologists have long been thought to be able to contribute to the articulation of the social context of technology use' (Räsänen and Nyce 2006, 399). Anthropological practices help to bridge the gap between actors and socio-structural points of view.

\subsection{Sustainability and Viability of the Intervention}

When we started the project, we initially planned for four years as further funding couldn't be promised at that time. One of the main goals, that we set for ourselves was to reach a point at which our partners could completely take over the computer club and keep it running - all by themselves. For us, this meant not only economically surviving but being sustainable, growing and evolving. Due to our specific research approach (Wulf et al. 2018), we seek to include 'users' from the beginning of a project. This is not only important for ensuring that the subsequent system or design will serve the needs of its users, but also crucial when it comes to letting projects go (Tongia and Subrahmanian 2006). From the start of our endeavour, we were trying to avoid going in an ICT4D direction that is often criticized (Botes and van Rensburg 2000; Tongia and Subrahmanian 2006; Toyama 2015). This critique is geared towards projects that are top-down, that insist on the primacy of researchers' ideas regarding how the entire project should work, and that believe that just bringing in technology will solve any problems (see also the critique offered by Morozov (2013)). In our case, we continually tried to state that we did not know best and that we valued everyone's input on decisions regarding the design and the intervention. Although we felt that we were perceived as experts, we openly and 
respectfully disagreed, trying not to adopt the role of paternalistic westerners, as criticized by Botes and van Rensburg (2000).

Sustainability was always a driving factor for us, not necessarily in terms of funding, but more in terms of the local people being able to take ownership of the project, with the entire intervention serving the people it was seeking to support. We made sure that we didn't interfere when we weren't on site, i.e., we only stepped in when we were asked to help, for instance with software updates.

We have recently witnessed new dynamics with regard to taking ownership of the space and letting it evolve, such as hiring a female tutor and offering use of the space to (future) local businesses. So far, a women's club has sporadically used the club and its media technology. This development needs to be concretized, with fixed dates and the involvement of the new tutor. Aside from this, our partners have approached us to say that they would like to provide Internet access in the club room for people to be able to use it more generally. In addition, the provided infrastructure is used for other projects as well, which are conducted by the NGO (e.g., a photography workshop with a teacher from a nearby village; joint cooking events with older female participants, where the tablets are used to look for recipes). So, we can confidently state that the technology and the space are being used for more than just the computer club and without our involvement. This is surely what local sustainable appropriation looks like.

\section{Limitations and Reflections}

Our paper provides a number of insights that are valuable to the CSCW community. However, both the study and the paper have limitations. Our methodology was primarily based on (participant) observation and informal interviews or, to be more precise, conversations, which couldn't be easily recorded and therefore were written down after the interviews or conversations took place. We have already noted above that this led to potential omissions that it is hard to overcome.

We have also noted that access to possible interviewees was limited, chiefly as a result of linguistic constraints, and that this led to a certain reliance upon others, notably our partners from the NGO. In the end, we had to trust in what we were being told by the employees from the NGO, though, through this trust, we were able to gain many meaningful insights about the power relations, daily life, technology usage and distribution, and also the impact of the computer club.

Evidently, following a qualitative and ethnographic approach makes it harder to measure and pinpoint changes and impacts. However, traditional quantitative methods, such as surveys would not work either, not only because of the local lack of literacy and language barrier, but also because of how such data is collected.

With the best of intentions, coming from the global North to a largely unknown country in the global South can, unwittingly, lead to biases in understanding. In the field of academia, where one is pushed to know what to do before one actually does know what to do, complicates this even more. In view of this, there is a constant need 
for reflection upon one's work and role, a constant need to remind oneself and one's colleagues to engage in such reflection, and a need to be continually alert to the possibility of bias in one's work. Such attentiveness can never wholly disappear (Irani et al. 2010; Philip et al. 2012).

When doing ethnographic, qualitative research, consideration of reflexivity is always essential. It is obvious from our study that we, the authors, do not originate from the region in Morocco that we studied and, when we entered the field, we entered with certain biases, resulting from our academic discipline, our background knowledge and our proposed research agenda. This is commonplace in interventions of this kind, but that is never an excuse to set the need for reflexivity aside when conducting ethnographic fieldwork (Vandenberg and Hall 2011; Bamkin et al. 2016; Lichterman 2017). Hopefully, it is clear in the above materials that we were eternally alert to this risk and at pains to minimize its impact.

\section{Conclusion and Future Work}

Creating and implementing a sustainable and viable socio-technical intervention can come with challenges and setbacks when following a specific work plan. However, expecting to be able to go by the book is hopelessly idealistic. The most important thing is to include all parties involved, not just for the sake of it, but for the sake of creating an enabling infrastructure that genuinely serves people.

Reflecting upon the last four years, the cooperation between the local partners and ourselves was successful. Even though some expectations might not have been shared, it did not compromise the collaborative work and the overall project, which also follows the tradition of Grounded Design (Rohde, Brödner, et al. 2016). On the contrary, because of the participatory research design approach and constant reflection, we were able to mutually forge the conditions for cooperation, bringing engaging media technology and a particular educational framework together. With the ongoing input of the NGO, the initiative could be adapted to local needs and existing offers in order to reach as many participants as possible, especially children. Sustainability was also achieved because our partners and the tutors appropriated the club and, with our help, acquired new skills and knowledge. The constant exchange between all of the partners, the field visits and the visit of members of the NGO to Germany supported these processes and helped both sites to gain a mutual understanding of one another.

Further developments have already been discussed with the local partners. By honouring their opinions and explaining our research concept, they have become motivated to sustain and extend the current existing space and to cooperate with local schools to link the ICT initiative more closely with existing educational institutions. The NGO is also engaged in an exchange with local businesses regarding how access might be provided to the available ICT to help them further develop their businesses. 


\section{Acknowledgments}

Gefördert durch die Deutsche Forschungsgemeinschaft (DFG) - Projektnummer 262513311 - SFB 1187.

Funded by the Deutsche Forschungsgemeinschaft (DFG, German Research Foundation) - Project-ID 262513311 - SFB 1187.

We would like to thank all partners and participants.

\section{Funding}

Open Access funding enabled and organized by Projekt DEAL.

Open Access This article is licensed under a Creative Commons Attribution 4.0 International License, which permits use, sharing, adaptation, distribution and reproduction in any medium or format, as long as you give appropriate credit to the original author(s) and the source, provide a link to the Creative Commons licence, and indicate if changes were made. The images or other third party material in this article are included in the article's Creative Commons licence, unless indicated otherwise in a credit line to the material. If material is not included in the article's Creative Commons licence and your intended use is not permitted by statutory regulation or exceeds the permitted use, you will need to obtain permission directly from the copyright holder. To view a copy of this licence, visit http:// creativecommons.org/licenses/by/4.0/.

\section{References}

Aal, Konstantin; Maximilian Krüger; Markus Rohde; Borislav Tadic; and Volker Wulf (2019). Social Media and ICT Usage in Conflicts Areas. In Information Technology for Peace and Security, ed. Christian Reuter. Wiesbaden: Springer Fachmedien Wiesbaden, pp. 383-401. https://doi.org/ 10.1007/978-3-658-25652-4_18.

Aal Konstantin; Marios Mouratidis; Anne Weibert; and Volker Wulf (2016). Challenges of CI Initiatives in a Political Unstable Situation - Case Study of a Computer Club in a Refugee Camp. In GROUP '16: Proceedings of the 19th International Conference on Supporting Group Work. New York, NY, USA: ACM, pp. 409-412. https://doi.org/10.1145/2957276.2996281.

Aal Konstantin; Thomas von Rekowski; George Yerousis; Volker Wulf; and Anne Weibert (2015). Bridging (Gender-Related) Barriers: A Comparative Study of Intercultural Computer Clubs. In GenderIT '15: Proceedings of the Third Conference on GenderIT. New York, NY, USA: ACM, pp. 17-23. https://doi.org/10.1145/2807565.2807708.

Aal, Konstantin; Sarah Rüller; Simon Holdermann; Peter Tolmie; Markus Rohde; Martin Zillinger; and Volker Wulf (2018). Challenges of an Educational ICT Intervention: The Establishment of a MediaSpace in the High Atlas. Ed. by Volkmar Pipek and Markus Rohde. International Reports on Socio-Informatics, Bonn: International Institute for Socio-Informatics, vol. 15, no. 2, pp. 1-20.

Aal, Konstantin; Marén Schorch; Esma Ben Hadj Elkilani; and Volker Wulf (2018). Facebook and the Mass Media in Tunisia. Media in Action, vol. 1, pp. 135-167. 
Aal Konstantin; George Yerousis; Kai Schubert; Dominik Hornung; Oliver Stickel; and Volker Wulf (2014). Come_in@ palestine: adapting a German computer club concept to a Palestinian refugee camp. In CABS '14: Proceedings of the 5th ACM international conference on Collaboration across boundaries: culture, distance \& technology, August 2014. New York: ACM, pp. 111-120.

Ahmed, Nova; A. M. Masudul Haque; and Luke Doyle (2015). Entering the dream world of computers. InICTD '15: Proceedings of the Seventh International Conference on Information and Communication Technologies and Development, Singapore, May 2015. New York: ACM Press, article no. 23, pp. 1-4. https://doi.org/10.1145/2737856.2737860.

Aker, Jenny C.; Christopher Ksoll; and Travis J. Lybbert (2012). Can mobile phones improve learning? Evidence from a field experiment in Niger. American Economic Journal: Applied Economics, vol. 4, pp. 94-120.

Bamkin, Marianne; Sally Maynard; and Anne Goulding (2016). Grounded theory and ethnography combined: A methodology to study children's interactions on children's mobile libraries. Journal of Documentation, vol. 72, pp. 214-231. https://doi.org/10.1108/JD-01-2015-0007.

Baranoff, Jennifer; R. Israel Gonzales; Jay Liu; Heidi Yang; and Jimin Zheng (2015). Lantern: Empowering Refugees Through Community-Generated Guidance Using Near Field Communication. In CHI EA '15: Proceedings of the 33rd Annual ACM Conference Extended Abstracts on Human Factors in Computing Systems. Seoul, April 2015. New York: ACM Press, pp. 7-12. https://doi.org/10.1145/2702613.2726950.

Baskerville Richard; Jan Pries-Heje; and John Venable (2009). Soft design science methodology. In DESRIST '09: Proceedings of the 4th international conference on design science research in information systems and technology, Philadelphia, Penn, May 2009. New York: ACM Press, Article no. 9, pp. 1-11.

Blecker Thorsten; and Guenter Graf (2003). Multi agent systems in internet based production environmentsan enabling infrastructure for mass customization. In $M C P C$ '03: Proceedings of the Second Interdisciplinary World Congress on Mass Customization and Personalization. Munich, 6-8 October 2003, pp. 1-27. http://citeseerx.ist.psu.edu/viewdoc/download?doi=10.1.1.3.8817\&rep=rep1\&type=pdf

Botes, Lucius; and Dingie van Rensburg (2000). Community participation in development: nine plagues and twelve commandments. Community Development Journal, vol. 35 pp. 41-58. https:// doi.org/10.1093/cdj/35.1.41.

Canada: Immigration and RefugeeBoard of Canada (2000). Morocco: Brief history of the Berbers including theirorigins and geographic location. 16 November 2000, MAR35753.E, available at: https://www.refworld.org/docid/3df4be668.html. Accessed 4 June 2021.

Chinapah, Vinayagum; and Jared O Odero (2016). Towards inclusive, quality ICT-based learning for rural transformation. Journal of Education and Research, vol. 5, pp. 107-125.

Cohen, Shana (2004). Searching for a different future: the rise of a global middle class in Morocco. Duke University Press.

Courbage, Youssef; and Emmanuel Todd (2008). Die unaufhaltsame Revolution: wie die Werte der Moderne die islamische Welt verändern: mit 8 Grafiken und 9 Tafeln sowie einer Karte. MünchenZürich: Piper.

Crabtree, Andy; and Tom Rodden (2002). Ethnography and design. In Proceedings of the International Workshop on 'Interpretive'Approaches to Information Systems and Computing Research', London: Association of Information Systems, pp. 70-74. http://citeseerx.ist.psu.edu/ viewdoc/download?doi=10.1.1.180.1386\&rep=replamp;\&type=pdf

Crawford, David (2008). Moroccan households in the world economy: labor and inequality in a Berber Village. Baton Rouge, Loisiana: Louisiana State University Press.

Crawford, David; and Katherine E. Hoffman (2000). Essentially Amazigh: urban Berbers and the global village. The Arab-African and Islamic Worlds: Interdisciplinary Studies. New York: Peter Lang, pp. 117-133. 
Dias, M. Bernardine; G. Ayorkor Mills-Tettey; and Joseph Mertz (2005). The TechBridgeWorld initiative: Broadening perspectives in computing technology education and research. In CWIT '05: Proceedings of the international symposium on Women and ICT creating global transformation, Baltimore, Maryland, 12- 14 June 2005. New York: ACM Press, pp. 17-es. https://doi.org/10.1145/1117417.1117434.

Dodson, Leslie L.; S. Revi Sterling; and John K. Bennett (2013). Minding the gaps: cultural, technical and gender-based barriers to mobile use in oral-language Berber communities in Morocco. In ICTD 13: Proceedings of the Sixth International Conference on Information and Communication Technologies and Development, Cape Town, South Africa. Full Papers, vol. 1. New York: ACM Press, pp. 79-88. https://doi.org/10.1145/2516604.2516626.

Dourish, Paul (2003). The Appropriation of Interactive Technologies: Some Lessons from Placeless Documents. Computer Supported Cooperative Work (CSCW), vol. 12, pp. 465-490. https://doi.org/ 10.1023/A:1026149119426.

Draxler Sebastian; Gunnar Stevens; Martin Stein; Alexander Boden; and David Randall (2012). Supporting the social context of technology appropriation: on a synthesis of sharing tools and tool knowledge. In CHI '12: Proceedings of the 2012 ACM annual conference on Human Factors in Computing Systems. Austin, Texas, USA, May 2012. New York ACM Press, pp. 2835-2844. https://doi.org/10.1145/2207676.2208687.

Easterly, William (2002). The elusive quest for growth: economists' adventures and misadventures in the tropics. MIT press.

Eickelman, Dale F. (1981). Moroccan Islam: Tradition and society in a pilgrimage center. Vol. 1. University of Texas Press.

Fisher, Karen E.; Katya Yefimova; and Eiad Yafi. 2016. Future's Butterflies: Co-Designing ICT Wayfaring Technology with Refugee Syrian Youth. In IDC '16: Proceedings of the The 15th International Conference on Interaction Design and Children. Manchester, United Kingdom, June 2016. New York ACM Press, pp. 25-36. https://doi.org/10.1145/2930674.2930701.

Geertz, Clifford (1977). The interpretation of cultures. New York: Basic books.

Gellner, Ernest (1969). Saints of the Atlas. Weidenfeld \& Nicolson.

Gertel, Jörg; and Ralf Hexel (2018). Coping with Uncertainty: Youth in the Middle East and North Africa. London: Saqi Books.

Goldkuhl Göran; and Mikael Lind (2010). A multi-grounded design research process. In DESRIST 2010: International Conference on Design Science Research in Information Systems. St. Gallen, Switzerland, 4-5 June 2010. Springer, 45-60.

Hammoudi, Abdellah (1997). Master and disciple: The cultural foundations of Moroccan authoritarianism. University of Chicago Press.

Heeks, Richard (2008). ICT4D 2.0: The Next Phase of Applying ICT for International Development. Computer, vol. 41, pp. 26-33. https://doi.org/10.1109/MC.2008.192.

Hoffman, Katherine E. (2008). We share walls: Language, land, and gender in Berber Morocco. John Wiley \& Sons.

Holdermann, Simon; and Konstantin Aal. 2019. Wie dekolonial kann Kooperation sein? TATuP Zeitschrift für Technikfolgenabschätzung in Theorie und Praxis, vol. 28, pp. 17-22.

Irani, Lilly; Janet Vertesi; Paul Dourish; Kavita Philip; and Rebecca E. Grinter (2010). Postcolonial computing: a lens on design and development. In CHI '10: Proceedings of the 28th international conference on Human factors in computing systems. Atlanta, Georgia, USA, April 2010. New York: ACM Press, pp. 1311-1320. https://doi.org/10.1145/1753326.1753522.

Johanson, B.; and A. Fox (2002). The Event Heap: a coordination infrastructure for interactive workspaces. In Proceedings Fourth IEEE Workshop on Mobile Computing Systems and Applications. Callicoon, NY, USA, 20-21 June 2002. IEEE Comput. Soc., pp. 83-93. https:// doi.org/10.1109/MCSA.2002.1017488. 
Kafai, Yasmin B.; Kylie A. Peppler; and Robbin N. Chapman, ed. (2009). The Computer Clubhouse: constructionism and creativity in youth communities. Technology, Education-Connections : The TEC Series. New York: Teachers College Press.

Kemmis, Stephen; and Robin McTaggart (2005). Participatory Action Research: Communicative Action and the Public Sphere. Sage Publications Ltd.

Kingdom of Morocco (2008). DigitalMorocco 2013: The National Strategy for Information Society and Digital Economy2009-2013. Ministry of Industry, Trade and New Technologies, Rabat. https://sherloc.unodc.org/cld/uploads/res/lessons-learned/mar/the-national-strategy-for-informationsociety-and-digital-economy_html/Maroc_CyberSecurity_2013_ENG.pdf. Accessed May 312021.

Lee, Raymond M. (1993). Doing research on sensitive topics. Sage.

Leonard, Dorothy A. (2011). Managing Knowledge Assets, Creativity and Innovation. Singapore etc.: World Scientific Publishing. https://doi.org/10.1142/7638.

Lichterman, Paul (2017). Interpretive reflexivity in ethnography. Ethnography, vol. 18, pp. 35-45. https://doi.org/10.1177/1466138115592418.

MacLean, Allan; Kathleen Carter; Lennart Lövstrand; and Thomas Moran (1990). User-tailorable systems: pressing the issues with buttons. In CHI '90: Proceedings of the SIGCHI conference on Human factors in computing systems Empowering people. Seattle, Washington, United States, March 1990. New York: ACM Press, pp. 175-182. https://doi.org/10.1145/97243.97271.

Maloney, John; Mitchel Resnick; Natalie Rusk; Brian Silverman; and Evelyn Eastmond (2010). The Scratch Programming Language and Environment. ACM Transactions on Computing Education (TOCE), vol. 10, article no. 16.

Mayring, Philipp (2000). Qualitative Content Analysis. Forum Qualitative Sozialforschung / Forum: Qualitative Social Research 1.

Menz, Georg (2010). Political and administrative structures: History and present situation. In Speth, Peter; Michael Christoph; and Bernd Diekkrüger (eds): Impacts of Global Change on the Hydrological Cycle in West and Northwest Africa. Berlin-Heidelberg: Springer, pp. 70-73.

Michalchik, Vera; Carlin Llorente; Patrick Lundh; and Julie Remold (2008). A place to be your best: Youth outcomes in the Computer Clubhouse. Prepared for The Computer Clubhouse Network, One Science Park, Boston, MA.

Mitleton-Kelly, E.; and M.-C. Papaefthimiou (2000). Co-Evolution and an Enabling Infrastructure: A Solution to Legacy? In Systems Engineering for Business Process Change, ed. Peter Henderson. London: Springer London, pp. 164-181. https://doi.org/10.1007/978-1-4471-0457-5_14.

Morozov, Evgeny (2013) To save everything, click here: the folly of technological solutionism. 1. ed. New York, NY: PublicAffairs.

NationMaster (2019). Morocco: Education: Illiteracy rates by sex. http://www.nationmaster.com/ country-info/profiles/Morocco/Education/Illiteracy-rates-by-sex. Accessed August 19. 2019

Ndaiga, Wachira; and Anne Salim (2015). Kids hacker camps in Kenya: hardware hacking effectiveness in skills transfer. In ICTD '15: Proceedings of the Seventh International Conference on Information and Communication Technologies and Development. Singapore, May 2015. ACM Press, article no. 52, pp. 1-4. https://doi.org/10.1145/2737856.2737873.

OECD (2018). Digital Government Review of Morocco. OECD Digital Government Studies. Paris: OECD Publishing. https://doi.org/10.1787/9789264298729-en.

Orlikowski, Wanda J. (1992). Learning from Notes: organizational issues in groupware implementation. In CSCW'92: Proceedings of the Conference on Computer-Supported Cooperative Work, 31 October-4 November 1992, Toronto, Canada. New York: ACM Press, pp. 362-369. https:// doi.org/10.1145/143457.143549.

Papert, Seymour (1980). Mindstorms: children, computers, and powerful ideas. New York: Basic Books, Inc.

Pennell, C. Richard (2003). Morocco: from Empire to independence. Oxford: Oneworld. 
Pfeifer Kristin (2011). "Wir sind keine Araber!”: amazighische Identitätskonstruktion in Marokko; im Spannunsfeld von internationalen Einflüssen und lokalen Ansprüchen. $\mathrm{PhD}$ Thesis, Universität Leipzig, Leipzig.

Philip, Kavita; Lilly Irani; and Paul Dourish (2012). Postcolonial Computing: A Tactical Survey. Science, Technology, \& Human Values, vol. 37, pp. 3-29. https://doi.org/10.1177/ 0162243910389594.

Pruneau, Diane; Boutaina El Jai; Abdellatif Khattabi; Sara Benbrahim; and Joanne Langis (2018). Using Design Thinking and Facebook to Accompany Women in Solving Water Problems in Morocco. In Handbook of Sustainability Science and Research, ed. Walter Leal Filho. Cham: Springer International Publishing, 25-40. https://doi.org/10.1007/978-3-319-63007-6_2.

Quinones, Pablo-Alejandro (2014). Cultivating practice \& shepherding technology use: supporting appropriation among unanticipated users. In CSCW '14: Proceedings of the 17th ACM conference on Computer supported cooperative work \& social computing. Baltimore, Maryland, USA, February 2014. New York: ACM Press, pp. 305-318. https://doi.org/10.1145/2531602.2531698.

Rabinow, Paul (2007). Reflections on Fieldwork in Morocco: with a New Preface by the Author. Univ of California Press.

Randall, David (2018). Investigation and Design. In Socio-informatics: a practice-based perspective on the design and use of IT artifacts, ed. Wulf Volker, Volkmar Pipek, David Randall, Markus Rohde, Kjeld Schmidt, and Gunnar Stevens. Oxford University Press, pp. 221-242.

Räsänen Minna; and James M. Nyce (2006). A new role for anthropology?: rewriting context and analysis in HCI research. In NordiCHI '06: Proceedings of the 4th Nordic conference on Humancomputer interaction: changing roles. Oslo, October 2006. New York: ACM Press, 175-184.

Rechberg, Isabel D. W.; and Jawad Syed (2014). Appropriation or participation of the individual in knowledge management. Management Decision, vol. 52, no. 3, pp. 426-445.

Resnick Mitchel; Natalie Rusk; and Stina Cooke (1998). The computer clubhouse: Technological fluency in the inner city. In D. Schon, B. Sanyal, and W. Mitchell (eds), High Technology and Low-Income Communities, MIT Press, pp. 263-285.

Rode Jennifer A.; Andrea Marshall; Anne Weibert; Konstantin Aal; Thomas von Rekowski; Houda El Mimouni; Akshay Sharma; Jordan Jobs; Alexis Schleeter; and Jennifer Booker (2015). From Computational Thinking to Computational Making. In UbiComp/ISWC'15 Adjunct: Adjunct Proceedings of the 2015 ACM International Joint Conference on Pervasive and Ubiquitous Computing and Proceedings of the 2015 ACM International Symposium on Wearable Computers. Osaka, September 2015. New York: ACM Press, 401-402. https://doi.org/10.1145/ 2800835.2800926.

Rohde, Markus; Konstantin Aal; Kaoru Misaki; Dave Randall; Anne Weibert; and Volker Wulf (2016). Out of Syria: Mobile Media in Use at the Time of Civil War. International Journal of Human-Computer Interaction, vol. 32, no. 7, pp. 515-531. https://doi.org/10.1080/ 10447318.2016.1177300.

Rohde, Markus; Peter Brödner; Gunnar Stevens; Matthias Betz; and Volker Wulf (2016). Grounded Design - a praxeological IS research perspective. Journal of Information Technology, vol. 32, no. 2, pp. 163-179. https://doi.org/10.1057/jit.2016.5.

Rüller Sarah, and Konstantin Aal (2020). Interventionistic Participatory Design (IPC). Tech Otherwise. https://doi.org/10.21428/93b2c832.007f3d63.

Rüller, Sarah; Konstantin Aal; and Simon Holdermann (2019). Reflections on a Design Case Study (Educational) ICT Intervention with Imazighen in Morocco. In C\&T '19: Proceedings of the 9th International Conference on Communities \& Technologies - Transforming Communities. Vienna, Austria, june 2019. New York: ACM Press, pp. 172-177. https://doi.org/10.1145/ 3328320.3328406 .

Schreier, Margrit (2014) Qualitative content analysis. The SAGE handbook of qualitative data analysis: $170-183$. 
Schubert, Kai; Anne Weibert; and Volker Wulf (2011). Locating computer clubs in multicultural neighborhoods: How collaborative project work fosters integration processes. International Journal of Human-Computer Studies, vol. 69, pp. 669-678. https://doi.org/10.1016/j.ijhcs.2010.12.007.

Slawson, Nicola (2016). In Morocco's Atlas mountains, Berber girls find the way out of rural poverty: an education. The Guardian, 19 June 2016, sec. World news.

Stevens, Gunnar; Michael Veith; and Volker Wulf (2005). Bridging among ethnic communities by cross-cultural communities of practice. In C\&T 2005: Proceedings of the Second Communities and Technologies Conference, Milano 2005. Dordrecht: Springer, pp. 377-396.

Stickel, Oliver; Dominik Hornung; Konstantin Aal; Markus Rohde; and Volker Wulf (2015). 3D Printing with Marginalized Children-An Exploration in a Palestinian Refugee Camp. In ECSCW 2015: Proceedings of the 14th European Conference on Computer Supported Cooperative Work Oslo, Norway, 19-23 September 2015, ed. Nina Boulus-Rødje, Gunnar Ellingsen, Tone Bratteteig, Margunn Aanestad, and Pernille Bjørn. Cham: Springer International Publishing, pp. 83-102.

Tchounikine, Pierren (2017). Designing for Appropriation: A Theoretical Account. Human-Computer Interaction, vol. 32, pp. 155-195. https://doi.org/10.1080/07370024.2016.1203263.

The World Bank (2021a). Morocco- Education Support Program Project (English). Washington, D.C.: World BankGroup. http://documents.worldbank.org/curated/en/908441561140203130/Morocco-Education-Support-Program-Project. Accessed May 312021.

The World Bank (2021b).MA-National Initiative for Human Development 2. P116201. Text/HTML. Washington, D.C.: World BankGroup. https://projects.worldbank.org/en/projects-operations/project-detail/P116201. Accessed May 312021

The World Bank (2019). Individuals using the Internet (\% of population) | Data. https:// data.worldbank.org/indicator/IT.NET.USER.ZS?locations=MA. Accessed 1 August 2019.

Tongia, Rahul; and Eswaran Subrahmanian. 2006. Information and Communications Technology for Development (ICT4D) - A Design Challenge? In 2006 International Conference on Information and Communication Technologies and Development. Berkeley, CA, USA, 25-26 May 2006: IEEE, pp. 243-255. https://doi.org/10.1109/ICTD.2006.301862.

Toyama, Kentaro (2015). Geek heresy: Rescuing social change from the cult of technology. New York: PublicAffairs.

Unbehaun, David; Konstantin Aal; Daryoush Daniel Vaziri; Rainer Wieching; Peter Tolmie; and Volker Wulf. 2018. Facilitating Collaboration and Social Experiences with Videogames in Dementia: Results and Implications from a Participatory Design Study. Proceedings of the ACM on Human-Computer Interaction, vol. 2, issue CSCW, November 2018, article no. 175, pp. 1-23. https://doi.org/10.1145/3274444.

Vandenberg, Helen E. R.; and Wendy A. Hall (2011). Critical ethnography: extending attention to bias and reinforcement of dominant power relations. Nurse Researcher, vol. 18, pp. 25-30. https:// doi.org/10.7748/nr2011.04.18.3.25.c8460.

Weibert, Anne; Konstantin Aal; Thomas von Rekowski; and Volker Wulf. 2015. "Hey, can we make that, please?": Upon Craft as a Means for Cross-cultural Community-Building. The Journal of Community Informatics, vol. 11, no. 2, pp. 1-9.

Weibert, Anne; Andrea Marshall; Konstantin Aal; Kai Schubert; and Jennifer Rode (2014). Sewing interest in E-textiles: analyzing making from a gendered perspective. In DIS 2014: Proceedings of the 2014 conference on Designing interactive systems, Vancouver, June 2014. New York: ACM Press, pp. 15-24.

Winschiers-Theophilus, Heike; Shilumbe Chivuno-Kuria; Gereon Koch Kapuire; Nicola J. Bidwell; and Edwin Blake (2010). Being participated: a community approach. In PDC '10: Proceedings of the 11th Biennial Participatory Design Conference. Sydney, Australia, November 2010. New York: ACM Press. https://doi.org/10.1145/1900441.1900443.

World Bank Group (2018). Kingdom of Morocco: Governing Towards Efficiency, Equity, Education and Endurance. http://hdl.handle.net/10986/29929 
Wulf, Volker; Konstantin Aal; Ibrahim Abu Kteish; Meryem Atam; Kai Schubert; Markus Rohde; George P Yerousis; and David Randall (2013). Fighting against the wall: Social media use by political activists in a Palestinian village. In CHI 2013: Proceedings of the The 31st Annual CHI Conference on Human Factors in Computing Systems. Paris, 27 April - 2 May 2013. New York: ACM Press, pp. 1979-1988.

Wulf, Volker; Kaoru Misaki; Meryem Atam; David Randall; and Markus Rohde (2013). 'On the ground'in Sidi Bouzid: investigating social media use during the Tunisian revolution. In CSCW 2013: Proceedings of the 2013 conference on Computer supported cooperative work, San Antonio, Texas, February 2013. New York: ACM Press, pp. 1409-1418..

Wulf, Volker; Volkmar Pipek; Dave Randall; Markus Rohde; Kjeld Schmidt; and Gunnar Stevens (eds) (2018). Socio-informatics: a practice-based perspective on the design and use of IT artifacts. First edition. Oxford: Oxford University Press.

Wulf, Volker; Markus Rohde; Volkmar Pipek; and Gunnar Stevens (2011). Engaging with practices: design case studies as a research framework in CSCW. In CSCW 2011: Proceedings of the ACM 2011 conference on Computer supported cooperative work, Hangzhou, China, March 2011, New York: ACM Press, pp. 505-512.

$\mathrm{Xu}$, Ying; Carleen Maitland; and Brian Tomaszewski (2015). Promoting participatory community building in refugee camps with mapping technology. In ICTD '15: Proceedings of the Seventh International Conference on Information and Communication Technologies and Development, Singapore, May 2015. New York: ACM Press, article no. 67. https://doi.org/ $10.1145 / 2737856.2737883$.

Yerousis, George; Konstantin Aal; Thomas von Rekowski; David W. Randall; Markus Rohde; and Volker Wulf (2015). Computer-Enabled Project Spaces: Connecting with Palestinian Refugees Across Camp Boundaries. In CHI '15: Proceedings of the 33rd Annual ACM Conference on Human Factors in Computing Systems, Seoul, April 2015. New York: ACM Press, pp. 3749-3758. https://doi.org/10.1145/2702123.2702283.

Zegura, Ellen W.; and Rebecca E. Grinter (2013). Community building for capacity building: case study of Liberia's iLab. In ICTD '13: Proceedings of the Sixth International Conference on Information and Communications Technologies and Development. Cape Town, December 2013, Notes - Volume 2. New York: ACM Press, pp. 171-174. https://doi.org/10.1145/ 2517899.2517936 .

Publisher's Note Springer Nature remains neutral with regard to jurisdictional claims in published maps and institutional affiliations. 